\title{
A match-mismatch theory of limbic system function
}

\author{
STEPHEN M. CORMIER \\ The George Washington University, Washington, D.C. 20006
}

\begin{abstract}
The contributions of three key limbic system structures-the amygdala, the hippocampus, and the septum - to human and animal behavior are analyzed, focusing primarily on learning and motivational variables. The amygdala is assumed to be part of a stimulus-analyzing system involved in the processing of reinforcers and salient cues. This system contributes to the formation of conditioned reinforcers and, thus, to the ability of arbitrary cues to control species specific behavior. The hippocampus is assumed to be part of a different stimulus-analyzing system which processes nonsalient stimuli. It habituates all stimuli not associated with reinforcement, this process occurring on any nonreinforced presentation. However, those nonsalient stimuli followed by reinforcement are registered as secondary cues. These cues are devoid of conditioned reinforcing properties. The septum is viewed as a coordinating structure that handles the flow of information between these two systems. The principles of operation of these structures are based on neurological and behavioral data from both animals and humans.
\end{abstract}

Although the limbic system, an interrelated group of neural structures comprising the "old" cortex, has long been regarded as, indeed, a system (Papez, 1937), conclusions about the exact functions it performs have been uncertain. For example, as recently as 1967 , Thompson (p. 558) could state that the function of the amygdala, an important limbic system structure, was almost completely undetermined. Actually, the claim that the structures in the old cortex were an integrated system was mainly based on their extensive neurological interconnections rather than on any clear understanding of function.

Over the course of the last 15 years, however, increasing surgical sophistication, as well as improved behavioral measurement, has slowly begun to clarify the function of at least some of the important limbic structures (e.g., Eleftheriou, 1972; Fried, 1972; Isaacson \& Pribram, 1975). Thus, this paper represents an attempt to put the pieces back together again. The discussion will center around the three most studied, and arguably most important, limbic structures: the amygdala, the septum, and the hippocampus. Their functions will first be considered separately, as far as possible, and then in relation to each other. An effort was made to attain at least qualitative precision in this regard at the molar level.

The theory of limbic system function presented here was constructed in the general belief that the complexities of behavior stem, in large part, from the interactions of a relatively few fundamental laws. In this view, a fundamental law should be consistent

The author's present address is: Personnel Research and Development Center, U.S. Office of Personnel Management, Washington, D.C. 20415. with different levels of description and should integrate a number of phenomena. Thus, the principles of limbic system function described here were formulated and/ or accepted because they were consistent with data at different descriptive levels. In other words, they can accommodate not only known physiological facts, but also purely behavioral data. Additionally, they attempt to integrate a wide range of neurological and behavioral data from both animals and humans, in order to narrow the field of plausible alternatives.

Several comments about the empirical evidence used are in order. First of all, both animal and human data were used whenever possible, mainly in the hope of showing large areas of agreement between the two in terms of limbic system functions. For example, it will be shown that there is probably much more correspondence between the hippocampal function of humans and infrahumans than is commonly believed to be the case. The differences, of course, are also pointed out.

Secondly, it should be noted that the theory is consistent with more evidence than is cited. An attempt was made to account for all major findings on these structures, especially when there was little controversy about the facts. Only space considerations prevented the inclusion of more citings from the literature.

The paper is organized in the following manner. First, there is a sequential discussion of three key limbic system structures: the amygdala, the hippocampus, and the septum. The proposed principles of operation for these structures will be given at the start of their respective sections. This will be followed in each case by an analysis of the data base that led to the formulation of those principles. Following this, a basis for understanding some of the major interconnections of these three structures will be offered. 


\section{THE AMYGDALA IN LEARNING AND MOTIVATION}

\section{Principles of Operation}

The present theory assumes that the amygdala is part of a stimulus-analyzing system which displays the following properties:

(1) It processes all unconditioned reinforcers, and the primary cues that occur in temporal proximity to the reinforcers, by augmenting neural and endocrine responses to their occurrence. The action of the reinforcer triggers the system to "fix" all of the salient details of the situation surrounding its occurrence by preventing the loss of this information from shortterm memory (STM).

(2) Since the primary cues must be residing in STM when the reinforcer occurs, there are relatively short temporal limits between the occurrence of a primary cue and its associated reinforcer that are possible and yet will allow the primary cues to be processed through this system.

(3) The system is critically important to stimuli acquiring conditioned reinforcing properties. Only stimuli processed through this system can become conditioned reinforcers.

(4) The cues in correlated temporal proximity to the unconditioned reinforcer take on the psychological properties of the reinforcer. This is due to the evocation of appropriate species-specific (emotional) behavior by the reinforcer while the primary cues are being processed. It is through this means that primary cues gain control over species-specific behavior.

(5) It influences certain homeostatic functions, but only in modulatory fashion, through its processing of motivationally significant stimuli.

(6) It inhibits habituative processes during the processing of the reinforcers and primary cues.

This system will henceforth be termed the reinforcer system.

\section{Amygdalar Involvement in Stimulus Processing}

Logically speaking, the effects that a particular neural structure has on behavior can be due to its influence on the processing of stimuli that control these behaviors or on the actual responses themselves. Theories of limbic system function have often wavered between assigning to limbic structures an involvement in stimulus processing or in response functions (e.g., Douglas \& Pribram, 1966; McCleary, 1966; Vanderwolf, Kramis, Gillespie, \& Bland, 1975). Since the present theory contends that the amygdala is part of a stimulus-analyzing system and is not directly involved in the elaboration of responses, it would be useful to present some of the supporting data.

First of all, there are neurons in the amygdala which are variously sensitive to simple and complex sensory stimuli in different modalities (Jacobs \&
McGinty, 1972; O’Keefe \& Bouma, 1969). Sanghera, Rolls, and Roper-Hall (1979) have shown that some neurons in the dorsolateral amygdala have sustained responses to objects that remain in the effective visual field for an extended period of time. These amygdala neurons are not particularly sensitive to the simple physical properties of the stimulus. This information is already processed in the primary sensory areas of the brain, in this case, the visual cortex. Instead, the amygdala neurons seem to display stimulus processing characteristics that are intermediate between those of initial sensory analysis and final assignment of motivational significance. The latter properties can be seen in hypothalamic neurons sensitive to visual input (Rolls, Burton, \& Mora, 1976). The response latencies of the amygdalar neurons do, in fact, fall between latencies of neurons in the inferotemporal cortex, which have output to the amygdala, and neurons in the lateral hypothalamus, which have input from the amygdala. This relationship raises the possibility that these structures are part of a connected system involved in stimulus analysis.

Electrical stimulation of certain areas of the amygdala commonly elicits orienting responses (OR) from unanesthetized animals (Ursin \& Kaada, 1960; Ursin, Webster, \& Ursin, 1967). It is important to note that the elicitation of the OR does not seem to be of a direct motoric nature, since the animals can respond appropriately to external stimuli presented during stimulation. Additionally, the elicited OR is generally a fully integrated response that is similar in form to those occurring in normal animals; that is, there is an initial arrest or pause in ongoing activities, followed by arousal, and then general searching or exploratory behaviors commence, as if to locate an object.

More generally, any theory positing a direct amygdalar involvement in response elaboration or sequencing has to cope with two findings in the experimental literature. First, a wide variety of integrated behaviors is known to be influenced by damage or stimulation to the amygdala. Second, there is a lack of any obvious difficulty in performing a particular response when it does occur (cf. Goddard, 1964; Kaada, 1972; Kling, 1972). As we shall see, it is the sheer variety of behaviors that is affected by amygdalar damage or stimulation that makes it more parsimonious to hypothesize a stimulus processing function instead of a response function for the amygdala, especially since the behavioral responses reveal no structural or topographic similarities.

\section{Amygdalar Involvement \\ in Species-Specific Behavior}

The amygdala's connection with species-specific or emotional behavior has been widely noted by researchers and theorists alike (e.g., Hughes \& Andy, 1979; Kaada, 1972; Kling, 1972), and, in fact, feeding, 
flight, defense, and sexual behaviors have all been elicited by stimulation of various sites in the amygdala. Since these motivated behaviors can still be induced in an organism with all tissue above the hypothalamus removed (Hess, 1957), a high-level involvement seems a logical description of the amygdala's role in these behaviors. In this connection, Gloor (1972) has speculated that the amygdala and other temporal lobe structures provide the link between the memorial representation of information in the neocortex and fundamental motivational mechanisms residing in the hypothalamus. Thus, there is widespread general agreement that the involvement of the amygdala in species-specific behaviors is important and a central part of its function. Let's examine specific evidence to see the form in which this involvement manifests itself.

Lesions to the amygdala can profoundly disrupt feeding, sexual, and social behaviors. These disruptions do not seem to be related to simple changes in drive level, especially since homeostatic functions are largely unimpaired in some instances (Grossman, 1964). For example, Schwartzbaum (1961), in studying amygdaloid hyperphagia, found that amygdalectomized monkeys were less selective about what they ate but, at the same time, were less responsive to prolonged food deprivation (cf. Czech, 1973; Leung \& Rogers, 1973). In this connection, it has long been noted that amygdalectomized animals are more likely to put both nonfood and food items in their mouths as though they had difficulty in distinguishing between them (cf. Kling, 1972).

The same kind of defect can be seen with sexual behavior. Aronson and Cooper (1979) tested the sexual response of male amygdalectomized cats in two different settings. The first involved the standard test of placing the male with an estrous female, and the second involved the sequential presentation of various sexually inappropriate objects arranged in a presumed gradient of attractiveness (i.e., stuffed toy, moving toy, tranquilized rabbit, male, and estrous female). In the standard test, amygdalectomized cats showed shorter latencies in initial mount than did controls. In the second test, the amygdalectomized cats, compared with controls, displayed an increased tendency to mount inappropriate objects, but no increases in sexual drive or level of performance were found. These cats still retained preferences when given a simultaneous choice between objects. This socalled "amygdaloid hypersexuality" has been noted in other species, including rats, monkeys and humans, although there are species-specific differences (Kling, 1968; Narabayashi, 1972; Schreiner \& Kling, 1973).

Amygdaloid lesions in rats and mice have been shown to be associated with decreased fear of novel situations or objects as well as with diminished flight tendencies (Slotnick, 1973; Ursin \& Divac, 1975), per- haps leading to the observed increase in open-field activity. This apparent reduction of fear arousal can be used to explain the finding that amygdalar lesions in the rat can decrease the severity of ulcers caused by physical restraint (Henke, 1980).

Many social behaviors are profoundly affected by damage to the amygdala. Tarr (1977) found that normal patterns of social behavior exhibited by the iguanid lizard (Sceloparus occidentalis) were abolished. by bilateral amygdaloid lesions. Dominance and submissive behavior no longer occurred in appropriate fashion. Shipley and Kolb (1977) noted changes in territorial aggression in male Syrian golden hamsters following amygdalectomy. Amygdalectomized monkeys often display confusion during social interactions, which can affect dominance relationships and lead to withdrawal from social contact (Kling, Lancaster, \& Benitone, 1970; Thompson, Bergland, \& Towfight, 1977). A simple reduction in aggressive behavior does not seem a likely explanation, since even appropriate submissive gestures are lacking (cf. Bunnell, Sodetz, \& Shalloway, 1970).

Many of these general kinds of deficits are noted in humans with damage to the amygdala. In this connection, it is useful to note that the arrangement of nuclei in the amygdala is quite uniform across most mammalian species, including humans (cf. Crosby \& Humphrey, 1941; Girgis, 1972). Stimulation of the amygdala can often evoke fear (Penfield \& Perot, 1963) and sometimes rage (Mark, Ervin, \& Sweet, 1972). Pleasant emotions have also been evoked by stimulation from implanted electrodes or by epileptic discharge in the amygdalar area (Daly, 1958; Stevens, Mark, Ervin, Pacheco, \& Suematso, 1969). Lesions of the amygdala seem to decrease general emotional expression (Narabayashi, 1972; Scoville, Dunsmore, Liberson, Henry, \& Pepe, 1953). Hughes and Andy (1979) studied responses to odors in nine patients who were amygdalotomized for the control of seizures. The lesions to the amygdala eliminated EEG fast background activity in response to odorants and caused a temporary increase in erroneous identification of odors. Hughes and Andy also studied clinical seizures that involved the amygdala and found that they were associated with both an increase of odor identification errors and an increased tendency to judge odors as intense or unpleasant.

\section{Amygdalar Processing of Unconditioned Stimuli}

The organism's ability to appropriately express species-specific behaviors is complexly determined and necessarily involves several of the processing characteristics ascribed to the amygdala in the principles of operation section. Since we are dealing with behaviors that are common to members of the species and that possess a substantial genetic component, the amygdala's processing of unconditioned stimuli is 
the focus of attention. According to match-mismatch theory, the amygdala is assumed to augment the organism's neural and endocrine response to unconditioned stimuli and to modulate related homeostatic functions. The studies cited above provide suggestive evidence that the amygdala is importantly involved in processing unconditioned stimuli, but more specific data is available.

Holmes and Egan (1973) and Pagano and Goult (1964) have shown that particular kinds of electrical activity in the amygdala, specifically, $30-$ to $40-\mathrm{Hz}$ spindling, seem to be correlated with a variety of species-specific behaviors and reinforcers (e.g., the presence and odor of food or sexual activity in the female cat). Norton (1970) reported increases in the amplitude of amygdala electrical activity that occurred after reinforced barpresses, but not after nonreinforced barpresses. Rolls (1972) demonstrated that individual amygdala neurons could be directly activated by stimulation of lateral hypothalamic sites which were associated with rewarding brain stimulation, eating, and drinking. Importantly, the firing pattern of these amygdala neurons did not appear to be significantly correlated with general arousal. As Margules and Olds (1962) have shown, there is often a correspondence between self-reward and food systems in the hypothalamus.

Lesion studies involving the amygdala present the same picture. Barrett (1969) and Downer (1961) have studied the effect of unilateral amygdalectomy in the split-brain monkey. In this preparation, since the optic chiasm is cut, visual input can only go to the ipsilateral hemisphere. If the monkey looks through only the eye on the side of the amygdalar lesion, then visual input is processed without benefit of the amygdala. Visual input processed through the other eye, however, can be processed by the intact amygdala on that side. In both studies, behavior of the monkeys with respect to positive or negative reinforcing stimuli was altered dramatically when visual input was restricted to the lesioned hemisphere. For example, the monkey studied by Downer had preoperatively shown a high degree of aggressive behavior towards humans in his presence. When visual input was restricted to the lesioned hemisphere, these aggressive behaviors disappeared and the monkey acted quite tame. However, the opening of the other eye led to a return of the aggression towards humans. These studies show clearly that a general emotional change in the organism cannot explain the behavioral deficit in response to emotionproducing stimuli in animals or humans with amygdalar damage.

Other studies provide evidence that the changed reactions to these reinforcing stimuli are not associated with simple attentional deficits. Rolls and Rolls (1973) demonstrated altered food preferences in rats with damage to the basolateral region of the amygdala. The amygdalar rats ate much more of novel, palatable food than did control rats; however, the differences in preferences were not connected with food sampling differences between groups. The rats with amygdalar damage sampled from all the food, as did the controls, but the controls ate the more familiar foods until a number of sessions had been run. It was as if the normal neophobia to different foods was eliminated by damage to the amygdala. In addition, changes in fear level or arousal had no effect on either group's food preferences. Belluzi (1972) showed that injections of carbachol or eserine, which potentiate cholinergic transmission, into the amygdala caused deficits in one-way avoidance but left performance of an appetitive visual discrimination unimpaired. In fact, animals and humans with amygdalar damage are quite capable of learning many different kinds of tasks, some of which can be quite difficult (cf. Andersen, 1978; Douglas \& Pribram, 1966). Thus, an explanation involving a generalized attentional deficit would have to explain why it would not be exhibited in these latter situations as well. Finally, it should be noted that amygdalar damage does not seem to affect the organism's ability to distinguish painful from pleasurable reinforcing stimuli; for example, rats with amygdalar lesions will flinch when receiving electric shock even though they do not avoid it the way control rats do (Kellicut \& Schwartzbaum, 1963).

Taken together, these studies provide evidence that the amygdala is importantly involved in the processing of reinforcers. Although organisms without a functioning amygdala seem to retain perceptions of the sensory qualities of reinforcers, somehow they are not able to remember how they should feel about them in an emotional sense. It should be noted that this interpretation of the deficit from amygdalar damage has received as much consideration from researchers as any others that have been advanced (cf. Holmes \& Egan, 1973). One general point which lends credence to this position is that the amygdala tends to receive its strongest sensory projections from the modality most involved in the identification of unconditioned stimuli for a particular species. Animals such as the rat, which depend heavily on olfactory stimuli for the expression of a wide variety of behaviors, have strong olfactory projections to the amygdala. On the other hand, species which depend most heavily on vision, such as the primate species, including humans, have strong visual projections to the amygdala.

\section{Amygdalar Mechanisms in the Response to Unconditioned Stimuli}

Even if we assume that the amygdala does play a role in connecting external reinforcing stimuli with appropriate emotional or species-specific behavior, there still remains the discovery of the actual process by which a functioning amygdala achieves this result. The theory states that the reinforcer system, including the amygdala, processes reinforcers by augment- 
ing the neural and endocrine response to them. This augmentation provides the means by which appropriate species-specific (emotional) behaviors will occur in response to unconditioned stimuli. Of course, the augmentation can be in an excitatory or inhibitory direction, depending on the nature of the reinforcer. Since we are dealing with unconditioned stimuli, the neural and endocrine response presumably produces behavioral or homeostatic responses which, from the start, are adaptive to the stimulus.

There are two issues, then, that we need to explore: First, to what extent does the amygdala affect neural and endocrine responses, and second, how does this effect produce appropriate behavior? Since the total amount of material relevant to these points is voluminous, to say the least, a necessarily selective but hopefully representative sample will be examined.

With regard to the first issue, the relationship of the amygdala and hypothalamus is probably the best place to start. The amygdala has two strong projections to the hypothalamus, namely, the stria terminalis and the ventral amygdalofugal pathway (VAF). Dreifuss, Murphy, and Gloor (1968) demonstrated that strong evoked responses could be obtained in the ventromedial hypothalamus after stimulation of cortical and central amygdaloid nuclei (cf. Egger, 1967; Murphy, Dreifuss, \& Gloor, 1968). Lesions of the ventromedial hypothalamus counteract the effects of amygdaloid stimulation (White \& Fisher, 1969).

The connection between the amygdala and the ventromedial hypothalamus has important implications, since this provides strong evidence that the amygdala is involved in the modulation of activity in the tuberal hypothalamus and thus in the pituitary axis. Some neurons in the tuberal hypothalamus have both typical neuronal functions and also secretory functions in which they produce, store, and release hormones (cf. Martini, Motta, \& Fraschini, 1970).

The amygdala has been shown to have a specific effect on a number of different hormones controlled by this region, for example, growth hormone and the sex hormones. With regard to growth hormone, Ehle, Mason, and Pennington (1977) demonstrated that stimulation of the amygdala in monkeys that provoked afterdischarge produced large increases in plasma growth hormone. Stimulation that was subthreshold for such afterdischarge produced smaller increases. Stimulation of the hippocampus did not produce these increases even when the electrical activity spread to the amygdala, which indicates that direct stimulation of amygdalar neurons was critical. As Meyer and Knobil (1967) have shown, noxious environmental stimuli can affect the levels of growth hormone released. Since amygdalar damage affects the response to such noxious stimuli, it is reasonable to assume that the amygdala is involved in the mediation of growth hormone level by environmental unconditioned stimuli.
The sex hormones have been intensively studied, both with respect to the influence of the amygdala on their release and to the effect of other stimulus factors (cf. Pfaff, Lewis, Diakow, \& Keiner, 1973; Zolovick, 1972). These hormones are useful, in the present context, because mating behavior in rats and other rodents is directly dependent upon them. Furthermore, the response components of mating seem to be highly stereotyped and under the external influence of particular stimuli. For example, the lordosis response of the female rat is dependent on estrogen and progesterone levels and on specific external stimulation, such as the male's forepaws on her flanks. Thus, changing the levels of the female sex hormones could reduce the incidence of lordosis even with the appropriate stimuli present.

The amygdala has been shown to have a significant impact on these sex hormones in both the male and the female. First of all, the amygdala, along with the hypothalamus-pituitary axis, seems to be a principle site for uptake of the female sex hormone estradiol (McEwen \& Pfaff, 1970; Stumpf \& Sar, 1971). These and other studies indicate that some neurons in these regions have receptor sites which bind molecules of the hormone. Second, these hormones have been shown to alter the excitability of amygdala neurons, which display an inverse relationship with hippocampal neurons in this respect (Terasawa \& Timiras, 1968). Third, lesions of the amygdala institute distinct changes in the levels of secretion of these hormones (Eleftheriou, Zolovick, \& Norman, 1967). Amygdalectomized female rats that had been ovariectomized did not show facilitated lordosis behavior after being treated with estradiol benzoate, in contrast with olfactory or septally lesioned female rats. Interestingly, the facilitation seen after septal lesions could be attenuated by amygdaloid lesions, indicating that the amygdala might be mediating the increased sensitivity to estrogen found in the septal rats (McGinnis, Nance, \& Gorski, 1978).

Evidence that the amygdala is mediating the effect of at least some kind of external stimulation on sex hormone levels is provided by Pasley, Powell, Cernosek, and Cernosek (1978). Grouped or singly caged male and female mice were given lesions of the amygdala and compared with controls on several measures of reproductive function. The intact female mice that had lived in groups under crowded conditions displayed reduced ovary weights relative not only to the singly caged intact females, but also to the amygdalectomized females that had lived in the group cages. In fact, there was no difference in ovary weights between the amygdalectomized females that had lived singly or in groups under crowded conditions. The same pattern was seen in the seminal vesicle weights of the males. Intact mice and sham operates living in groups had reduced vesicle weights compared with amygdalectomized males living in 
similar conditions. Levels of plasma luteinizing hormone also correspond to the morphological data. These data strongly suggest that amygdalectomized mice show a diminished response to stressful stimuli, relative to normal mice, and that this in turn can affect sex hormone levels.

There is strong evidence to suggest that the amygdala, through its influence over the pituitary-adrenal system, has an important role in the processing of stimuli that increase stress in the organism. In particular, a number of researchers have examined amygdalar modulation of adrenocorticotropin hormone (ACTH) secretion and plasma corticosterone levels. It has been shown clearly that adrenocortical secretion increases in response to stimuli that are associated with fear and anxiety such as shock or novel stimuli (cf. Hennesy, King, McClure, \& Levine, 1977; Redgate, 1970; Smith, 1973), although such secretion is not graded according to stimulus intensity (Bassett, Cairncross, \& King, 1973; Hennesy, Levin, \& Levine, 1977).

Although the degree of corticoid response is not sensitive to a number of stimulus parameters such as intensity, it nevertheless is the case that the history of the organism, in a general sense as well as with respect to a particular stimulus, plays an important role in such responses (cf. Hennesy \& Levine, 1979). For example, handling of rats in the first 3 weeks after birth can permanently attenuate the adrenocortical response to novel stimuli compared with the response of nonhandled rats (Denenberg \& Haltmeyer, 1967), presumably through some sort of habituative process. On the other hand, monkeys who were judged highly aggressive had higher corticoid responses to training on an operant avoidance task than did less aggressive monkeys (Levine, Gordon, Peterson, \& Rose, 1970). Gibbons and McHugh (1962) found that severely depressed humans tend to have higher levels of plasma corticoids than do mildly depressed humans. Dallman and Jones (1973) have demonstrated an apparent increase in responsivity of ACTH-releasing mechanisms to repeated exposure to stressful stimuli.

Corticoid response to the presentation or omission of unconditioned stimuli has been observed in learning paradigms. The omission of reward in an operant task increases pituitary-adrenal activity (Coover, Goldman, \& Levine, 1971), as does changing from FI to VI schedules (Davis, Memmott, McFadden, \& Levine, 1976). Interestingly, changing from VI to FI schedules does not cause such increases, perhaps because of the increased predictability of reinforcer occurrence. Adrenocortical response in avoidance situations can be increased by modifying the avoidance contingency so that on some trials shock no longer can be consistently avoided (Hanson, Larson, \& Snowden, 1976). However, in situations in which active avoidance behavior has stabilized and is suc- cessful, attenuation of the pituitary-adrenal response is found. Koranyi, Endroczi, Lissak, and Szepes (1967) demonstrated that mice receiving ACTH prior to the delivery of shock in the passive avoidance paradigm showed greater suppression of approach behaviors than did controls. Guth, Seward, and Levine (1971) injected ACTH 10 min prior to the delivery of punishment and obtained significantly greater response suppression than they did with controls.

Taken together, these results support the idea that adrenal corticoid response is increased when an organism is exposed to a more stressful situation and that such activity can be related to learning about stressful events. In turn, it can be shown that the amygdala plays a profound role in the kinds of pituitary-adrenal activity discussed.

Allen and Allen (1974) studied the effect of unilateral and bilateral lesions of the amygdala on the release of ACTH following stress induced by leg break, ether, or application of a tourniquet. Bilateral lesions blocked increases in ACTH release in response to the leg break but not to the other two stressors, indicating that the amygdala is important to the ACTH response to neurogenic, but not systemic, stress. In other words, the amygdala is more likely involved in the response to direct, external stress than to changes in the internal milieu. These results were not found after unilateral lesions. Allen and Allen (1975) showed that the VAF pathway between the amygdala and hypothalamus was critically involved in the ACTH response to stress.

Electrical stimulation of the amygdala has been shown to increase adrenocorticotropic activity in a number of species, including humans (Rubin, Mandell, \& Crandall, 1966). Bouillé and Baylé (1973) have shown that stimulation of the avian amygdalar homo$\log$, or archistriatum, in pigeons has a similar effect. The injection of ACTH into amygdalectomized rats has been found to reverse the deficits in passive avoidance caused by amygdaloid lesions (Bush, Lovely, \& Pagano, 1973). Burt and Smotherman (1980) showed that ACTH injection could reverse a deficit in conditioned taste aversion in rats with bilateral amygdalar lesions. In this connection, it should be noted that the role of ACTH in acquisition and recovery of conditioned taste aversion has been independently established (Smotherman, Hennesy, \& Levine, 1976).

Werka, Skar, and Ursin (1978) demonstrated that amygdalar lesions in rats led to deficits in one-way avoidance, with the greatest deficit appearing in rats with lesions in the central area. Lesions of the central amygdala decrease corticosterone levels and reduce freezing (Coover, Ursin, \& Levine, 1973). Thus, the deficit in one-way avoidance is probably due to reduced fear of shock. As Werka et al. note, the findings of improved avoidance in amygdalectomized 
rats by Grossman (1972) could very well be due to the difficult task used; reduced fear in this case would facilitate learning relative to controls.

The evidence cited above clearly indicates the involvement of the amygdala in the neural and endocrine responses to stressful or arousing stimuli. How might damage to the amygdala specifically produce the disruption of species-specific behavior that has been noted in numerous studies?

It is hypothesized that the amygdalar augmentation of response to reinforcers and stressful stimuli allows the formation of a mood state, which increases the probability of response of particular behaviors. A mood state is defined as the product of the effects of a neurochemical on specific brain areas combined with the neural processing of particular unconditioned stimuli. This mood state is a relatively sustained response, which provides the support for an integrated series of species-specific behaviors to take place over time. For example, stimulation of certain hypothalamic areas can produce a complete defense response, including all autonomic and postural elements. However, the defense response in the animal terminates the moment the stimulation is stopped. Amygdalar stimulation can also produce a defense reaction, but this develops slowly during stimulation and outlasts the period of stimulation by several minutes (Hilton \& Zbrozyna, 1963).

It is becoming increasingly clear that many motivated behaviors are under the control of external stimuli as much as, if not more than, they are under the control of internal homeostatic forces (cf. Fitzsimmons, 1972; Mogenson \& Phillips, 1976). To take just one example, it has been shown that the urine odor of a strange or novel male mouse can block prolactin secretion and thus terminate an early pregnancy in a female mouse (Bronson, 1968). Many sexual behaviors are under the control of various pheromones in rodents.

This line of argument indicates that the amygdala is responsible for the processing of external unconditioned stimuli by augmentation of the neural and endocrine response to them. This augmentation leads to the creation of a mood state that makes certain species-specific behaviors more likely to occur. The destruction of the amygdala interrupts this process by inhibiting the formation of an appropriate mood state, and this creates a situation in which these behaviors are not made prepotent. This accounts for the common observation of inappropriate speciesspecific responding on the part of organisms with amygdalar damage.

\section{Amygdalar Processing of Primary Cues}

The principles of operation for the amygdala indicate that it processes not only unconditioned stimuli, but also primary cues in close temporal proximity to the occurrence of the reinforcer. The pro- cessing of the reinforcer acts to preserve the information that exists in STM at the time of its occurrence. STM can be defined as containing information that does not need to be retrieved to be available to the organism. Two related points flow out of this proposed processing of stimuli that are in temporal proximity to the reinforcer, namely, the conditioned reinforcing properties of these stimuli and their ability to control species-specific behaviors.

The properties of primary cues have been intensively investigated at the behavioral level in a number of species. It has long been known, for example, that neutral stimuli paired with reinforcers can acquire the functional properties of those reinforcers. This process manifests itself in two ways. First, the paired stimulus or cue can reinforce the learning of other behaviors in the absence of an unconditioned reinforcer (e.g., Saltzman, 1949). Second, it can often come to control many of the species-specific response components elicited by the reinforcer. Many theorists hypothesize that the reinforcer imparts to temporally proximate stimuli certain incentive qualities that can arouse the appropriate species-specific behaviors (Bindra, 1972; Bolles, 1972; Shettleworth, 1975).

Pavlov (1941) noted that a dog, trained to respond to a metronome acting as a CS for the occurrence of food, would lick and attempt to bite the metronome as if it were food. The point to be considered here is that the animal performed these movements in relation to the CS rather than the feeder where the food arrived. Brown and Jenkins (1968) and Jenkins and Moore (1973) reported similar findings using the keypeck response of pigeons. An example of the generality of this phenomenon is provided by Peterson, Ackil, Frommer, and Hearst (1972), who used electrical stimulation of the hypothalamus as the reinforcer. The insertion of a retractable bar was the CS. After a number of pairings, the rats began to approach the bar; however, they did not lick or gnaw it as they did when consumable reinforcers were used. Instead, they tended to engage in exploratory movements which included fragments of movements that occurred during hypothalamic stimulation. Although this property is not universally present in conditioned reinforcers, it occurs often enough to perhaps be called a typical attribute (cf. Dunham, 1977).

In the previous sections, it was shown that the amygdala played an important role in the processing of unconditioned stimuli, and thus in the elaboration of many species-specific behaviors. The current theory hypothesizes that the amygdala also plays an important role in the association of primary cues with the reinforcer, particularly with regard to their conditioned reinforcing properties. Since the reinforcer imparts certain properties to the primary cues which make them functionally similar to the reinforcer, it seems highly possible that the amygdala's response to the reinforcer is a substrate for this phenomenon. 
If this is, in fact, the case, damage to the amygdala should impair the process by which primary cues become conditioned reinforcers and thus functionally similar to the co-occurring reinforcer.

Cohen $(1974,1975)$ showed that lesions of the posterior-medial regions of the archistriatum in pigeons produced severe decrements in the conditioning that accrued to a visual stimulus paired with electric shock. Other limbic structures, with the possible exception of the septum, seemed to play little role in the development of conditioning to the primary cue. Kellicut and Schwartzbaum (1963) reported that formation of a CER to a tone paired with shock showed a severe deficit in rats with amygdaloid lesions, indicating that the tone had not acquired significant conditioning. Even increasing the shock intensity or duration failed to have an effect. The responding of amygdaloid rats for food during the CS period could only be diminished by punishing each response. McGowan, Hankins, and Garcia (1972) demonstrated that rats with amygdalar lesions were deficient in acquiring conditioned suppression of drinking when a CS noise that had been paired with shock was presented. They were also deficient in acquiring an aversion to a flavor associated with illness. Spevack, Campbell, and Drake (1975) demonstrated that amygdalectomized rats that displayed deficits in CER formation had normal habituation to the stimulus used as CS. This last study would seem to indicate that the deficit in conditioning in amygdala-lesioned organisms is not due to attentional factors. Could the inability to suppress food-motivated behavior by the CS paired with shock be the result of an increased motivation of the rat to obtain the food? This seems highly unlikely, since amygdala-lesioned animals display reduced responsiveness to food deprivation (Schwartzbaum, 1961) and also seem to have flattened preference for favored reinforcers (White, 1971).

Additionally, animals with amygdalar damage seem to be less affected by cues associated with reinforcement delay or omission (Goomas, Hamm, \& Skinner, 1980; Henke, 1973). Somewhat more indirect evidence is provided by McDonough and Manning (1979), who studied amygdalectomized rats on an appetitive FI schedule. The presentation of noncontingent reinforcement on the FI schedule reduced the contingent responding of the amygdalar rats significantly more than it did controls, indicating that the conditioned reinforcers present on the schedule had less control over behavior.

\section{Temporal Proximity to Reinforcement and Amygdalar Processing}

It was stated in the principles of operation that the primary cues that occur in correlated temporal proximity to the reinforcer are processed through the amygdala and reinforcer system. Other theories of amygdala function such as that of Douglas and Pribram (1966) have assumed that temporal proximity (i.e., contiguity) was sufficient for registration of these cues. However, behavioral research by Kamin (1969) and Rescorla $(1967,1972)$ cast doubt on this point. For example, Rescorla (1967) demonstrated that a CS that was contiguous but not correlated with the occurrence of a US had negligible conditioning accrue to it. In other words, when there is as much chance of the US's occurring without the CS as with it, conditioning does not occur to that CS. Thus, correlation, rather than just contiguity, is a necessary condition for continued processing through the reinforcer system.

The assumption that the reinforcer system processes only those salient cues that are in correlated temporal proximity to the occurrence of the reinforcer has some definite implications for the behavior of organisms. For example, Douglas and Pribram (1969), using discrimination tasks with monkeys, tested the hypothesis that the amygdala acts to preserve important events from the interference of succeeding events that are novel but irrelevant. They found that amygdalectomized monkeys showed abnormally high distractibility on sequential discrimination tasks. The distractibility was mainly with respect to at least occasionally reinforced irrelevant cues, since nonreinforced irrelevant cues did not affect amygdalar lesioned monkeys differently from controls (Douglas, Barrett, Pribram, \& Cerny, 1969). This inability to keep focused on a task also shows up in humans with amygdalar damage.

Andersen (1978) investigated the cognitive functioning of human patients before and after they received amygdalotomy for the treatment of epileptic seizures. Although their general intelligence remained at about the same level postoperatively, performance on certain tasks declined markedly. For example, in continuous graphic performance, in which the patients had to copy a particular repeating pattern indefinitely, there was a large difference in the abilities of controls and amygdalectomized patients to correctly repeat the pattern, although deficits in pattern reproduction per se or in motor performance were not evident. In verbal recognition and recall tasks, subjects tended to improve their performance when given a second test some time after an initial test of memory. That is, if they were asked to distinguish list words from distractors, they were helped in a second recognition test by seeing the targets and distractors on an initial recognition test. There is some evidence to suggest that amygdala-damaged humans have trouble bringing memories to consciousness (cf. Kling, 1972).

These various results suggest that the amygdala does not affect all cue processing, since even certain difficult tasks are acquired quite well. Instead, it selectively affects the processing of those stimuli that 
most strongly control performance on a task. Since amygdalectomized monkeys were most affected by irrelevant cues that were at least occasionally reinforced, it is logical to assume that the amygdala is involved in keeping attention focused on the cue or cues that have the closest relationship with the reinforcing stimulus. The present theory suggests that the disruption of the process by which primary cues acquire conditioned reinforcing properties is the basis for the increased distractibility of the amygdalectomized monkeys' performance. The amygdalectomized monkeys do not come under strong stimulus control from the main relevant cue, and thus they divide their responding among the various cues that co-occur at some point with the reinforcer. By implication, the amygdala and reinforcer system are not involved in cue processing that does not meet the requirements laid out in the principles of operation. Therefore, there would seem to be a need to identify two different types of cues or cue properties, depending on whether the stimuli were processed through the reinforcer system or not.

There is some evidence at the behavioral level to suggest that there are indeed two types of cues. Rescorla (1973) and Rizley and Rescorla (1972) made a detailed analysis of various cue properties while studying second-order conditioning. In this paradigm, a $\mathrm{CS}_{1}$ is paired with a US until the $\mathrm{CS}_{1}$ is able to control a CR. Only at this point is a $\mathrm{CS}_{2}$ introduced and paired with a $C S_{1}$. Rizley and Rescorla found that after both the $\mathrm{CS}_{1}$ and $\mathrm{CS}_{2}$ controlled a $\mathrm{CR}$, extinction of the $\mathrm{CS}_{1}$ left the $\mathrm{CS}_{2}$ unaffected and still able to control the CR. Additionally, Rescorla found that habituation of the (noise) US also left the strength of the $\mathrm{CS}_{2}$ unaffected. However, habituation of the US left the $\mathrm{CS}_{1}$ significantly attenuated.

This pattern of results indicates that the strength of primary cues is heavily dependent on the current strength of the US. In terms of the current model, the data support the idea that primary cues are processed with the reinforcer in a way different from that of the secondary cues. The current position is that both primary cues and reinforcers are processed through the amygdala and reinforcer system. (The properties of the $\mathrm{CS}_{2}$ will be discussed in the section on the hippocampus.)

It should be noted that independent support for the identification of two cue types is provided by the instrumental analogue of classical higher order conditioning, namely, the chain schedule. This schedule is characterized by the association of different external discriminative stimuli with instrumental responses in an extended series. Gollub (1977) has noted the great difficulty in maintaining response rates of pigeons in the initial components of a five-component chain schedule. The initial stimuli are typically not conditioned reinforcers, even when they maintain moderate rates of responding. Kelleher and Fry (1962) and Killeen (1969) found that it was the temporal distance from the occurrence of reinforcement that was the critical factor, not the number of components.

The last principle unmentioned is that habituation is blocked when the reinforcer system and amygdala are activated. This point was included in the Douglas and Pribram (1966) theory and needs little elaboration, since the positive results of every conditioning experiment support it.

\section{THE HIPPOCAMPUS IN LEARNING AND MOTIVATION}

\section{Principles of Operation}

The present theory assumes that the hippocampus is part of a stimulus-analyzing system that displays the following properties:

(1) It processes stimuli that are not followed by reinforcers, and it habituates (extinguishes) them. This can occur either when novel, nonreinforced stimuli are encountered or in the extinction situation in which reinforcement is no longer paired with the conditioned stimuli or the discriminative stimuli that preceded it.

(2) It reduces the associative value of cues in declining correlation with the occurrence of reinforcement to a level sustainable by the new correlation between cue and reinforcer.

(3) It processes secondary cues that are not in close temporal proximity to the reinforcer, and which thus fall outside the limits of the reinforcer system. Nonsalient and background stimuli are also possible secondary cues. The secondary cues initially are processed in the same way as the nonreinforced stimuli: however, they are registered as cues to reinforcement when primary cues are present to inhibit habituative processes. (Primary cues are processed through the reinforcer system whose activation inhibits habituation.)

(4) It cannot impart conditioned reinforcing properties to the secondary cues, since only stimuli processed through the reinforcer system can acquire such properties. The secondary cues function only as discriminative stimuli. Therefore, stimuli processed through this system cannot gain direct control over nonarbitrary species-specific responses, but only over arbitrary, voluntary responses. This is in contrast with reinforcing stimuli, which can directly control both types of behavior.

(5) It receives information concerning the performance of conditioned or reinforced responses. This information is used to identify the controlling stimuli that signal the occurrence of a reinforcer, not as a means of modulating motoric output. This process results in the protection of those stimuli from interference or habituation as long as the reinforcer system is activated.

(6) The hippocampal theta waves occurring during various activities in different species, most typically with voluntary movements, are a reflection of a 
general capability of cue processing through this system. It is a nonspecific state in which the theta waves indicate processing capability, not necessarily actual processing of changes in the associative strength of stimuli.

(7) It has primarily an indirect role in motivational or homeostatic functions resulting from its general habituative function.

This system will henceforth be termed the habituative system.

\section{Hippocampal Involvement in Stimulus Processing}

Since it is concluded that the hippocampus, like the amygdala, is part of a stimulus processing system, some evidence should be provided to support that basic assumption. Vinogradova (1975) has shown that the majority of neurons in the dorsal hippocampus are sensitive to stimuli in a number of different modalities. Green and Machne (1955) showed that bursts of neuronal activity that were correlated with the hippocampal theta rhythm could be evoked for all types of sensory stimuli. Adey, Dunlop, and Hendrix (1960) and Vinogradova (1975) reported that on initial learning trials electrical changes occurred which gradually faded. Any of the stimulus changes used by Sokolov (1969) to cause dishabituation could make these evoked responses reappear. Stimulation of the hippocampus can create changes in the activity of neurons in other areas of the brain that process sensory information. Hippocampal stimulation has been shown to modify evoked responses to appropriate stimuli in the auditory cortex (Parmeggiani \& Rapisardi, 1969), the visual cortex (Fleming \& Bigler, 1974), and hypothalamic neurons sensitive to olfactory stimulation (Komisaruk \& Beyer, 1972).

As with the amygdala, a number of researchers have hypothesized a direct involvement of the hippocampus in the elaboration of response output (e.g., McCleary, 1966; Vanderwolf et al., 1975). This hypothesis has more direct support in the case of the hippocampus, if only because the neuronal activity of this structure seems to be correlated with a number of overt responses (cf. Berger \& Thompson, 1978; Vanderwolf, 1971). The problem with viewing this response-related activity as essential to the behavioral response is quite simply that damage or disruptive stimulation to the hippocampus does not seem to affect response output per se, even when the specific neuronal activity correlated with the response is eliminated. Livesey (1975) showed that stimulation of the hippocampus did not have an apparent effect on the execution of a response in a simultaneous discrimination task. However, it did affect cue selection. Similar findings have been reported after hippocampal lesions (Spevack \& Pribram, 1973). Salafia, Romanov, Tynan, and Host (1977) have shown that nosttrial electrical stimulation of the hippocampus immediately after CS-US pairings causes massive disruption of conditioning, compared with that of controls. The stimulation exerts its effect through postponement of CR emergence. Once the CR begins to occur, conditioning seems to proceed normally, even with continued stimulation. Thus, the hippocampus seems to be importantly involved in stimulus processing, since in its functional absence, cue selection and processing seem fundamentally altered. Later on, we will consider the question of why responserelated activity is found in the hippocampus at all.

\section{Novel Stimuli and the Hippocampus}

From the principles of operation, it can be seen that the hippocampus is assumed to play an important role in the processing of nonreinforced stimuli. As it turns out, the nonreinforcement of a stimulus can come about in a number of ways: in the extinction situation; on nonreinforced trials on a partial reinforcement schedule; or simply with stimuli that have not been associated with reinforcement to begin with, such as those encountered in exploratory activities. This last category will be the focus of this section.

If the hippocampus is involved in the processing and habituation of novel, nonreinforced stimuli, this process should reflect itself in exploratory and investigatory tendencies at the behavioral level (cf. Douglas, 1967, 1972; Kimble, 1968). Hippocampectomized rats habituate more slowly in an openfield situation and engage in more repetitive behaviors than do normal rats (Blanchard, Blanchard, Lee, \& Fukunaga, 1977).

Interestingly, exploration by hippocampectomized rats is greater in the dark than during the day (Isaacson \& McClearn, 1978). Iuvone and van Hartesveldt (1977) have demonstrated that hippocampal lesions in rats result in a disruption of their normal diurnal fluctuation in activity, primarily by increasing the amount of activity observed in the morning before the onset of light. Suess and Berlyne (1978) showed that light-related response decrements in exploratory behavior of hippocampally lesioned rats towards different novel stimuli could be found together with impaired habituation. In terms of the present theory, this effect could be due to the operation of the reinforcer system acting without the inhibitory balance provided by the habituatory system and hippocampus. If the hippocampus is processing and habituating novel stimuli, then damage to it should disrupt this process. To the extent that the novel situation is slightly fear evoking, which initially it typically is (Blanchard, Kelly, \& Blanchard, 1974), the reinforcer system is engaged. If this initial fear reaction is not habituated normally, then exploratory behavior should be inhibited as a result. However, in the dark there is a reduction of sensory stimulation, which should lead to a decrease in arousal and fear, particularly in a nocturnal animal such as the rat. Thus, 
the hippocampectomized rat is more likely to engage in exploratory behaviors at this time.

Spontaneous alternation is a rather specific example of the general exploratory tendency to avoid exposure to the same stimulus environment (Dember, 1956). The test is usually conducted in a T-maze, in which normal rats strongly tend to explore alternate arms from trial to trial, choosing a maze arm different from that in the previous trial approximately $85 \%$ of the time. In contrast, hippocampally lesioned rats seem to prefer the same maze arm on the next trial about $60 \%$ of the time (Douglas, 1975). Iseroff (1979) and Kirkby, Stein, Kimble, and Kimble (1967) studied spontaneous alternation in hippocampally lesioned rats following various periods of confinement in the first chosen arm of a T-maze. Only when the lesioned rats were confined for at least $10 \mathrm{~min}$ did their alternation rate equal that of controls. Presumably, the increased amount of time allowed the reduction of novelty to take place, indicating that the habituative processes to novel stimuli are considerably weakened in hippocampectomized rats. In line with the current theory is the fact that lesions of the amygdala do not have any material effect on spontaneous alternation (Douglas, 1975).

\section{Hippocampal Involvement in the Reduction of Associative Strength of Stimuli}

The involvement of the hippocampus in habituation and extinction has been perhaps the most common property ascribed to this structure (cf. Douglas \& Pribram, 1966; Kimble, 1968). There is a wide body of empirical evidence supporting this general assumption. For example, Ellen and Wilson (1963) demonstrated extinction deficits on several operant schedules in hippocampally lesioned animals. Similar findings of increased resistance to extinction have been found in discrimination tasks (Douglas \& Pribram, 1966), in classical conditioning (Schmaltz $\&$ Theios, 1972), and in both spatial and nonspatial reversal tasks (Becker \& Olton, 1980; Lash, 1964). The Becker and Olton study provides support for the idea that the reversal deficit in hippocampectomized animals is of a general nature and is not confined to spatial tasks.

Kohler (1976a) has reported that hippocampectomy of rats delayed habituation of the OR, although it seemed to have no effect on habituation of locomotor activity, rearing, or the startle response. This would seem to contradict assertions that the hippocampus is, in fact, involved in habituative processes. The present theory makes clear, though, that it is the habituation of stimuli that is mediated by the hippocampus. Thus, a novel stimulus or former cue to reinforcement has its motivational or discriminative value decreased by the action of the hippocampus. However, the performance or nonperformance of motor activity such as locomotion or rearing is not considered to be directly under the control of the hippocampus, since it is part of a stimulus-analyzing system.

In this context, it is significant that habituation of the OR was affected, since the OR has been shown to be intimately involved in the processing and learning of environmental stimuli (cf. Sokolov, 1969). It would have to be shown that nonreinforced stimuli habituate normally after hippocampal damage, a showing opposite to what has been obtained empirically. For example, rats with hippocampal lesions display deficits on latent inhibition. In this paradigm, a stimulus is habituated and then used as a CS for the occurrence of a US. Normal animals have reduced conditioning to the habituated CS. Solomon and Moore (1975) have shown, however, that hippocampectomized rabbits do not habituate as readily to the novel stimulus and thus do not display the normal reduction in conditioning when it is used as a CS. Ackil, Mellgren, Halgran, and Frommer (1969) found a similar effect when using an avoidance task.

The present theory assumes that the hippocampus is involved in habituation and extinction in a very precise and well-ordered way. Unlike most theories dealing with this function, the current theory assumes that the habituative and extinctive processes of the hippocampus are not limited to the typical situations discussed previously; instead, it is hypothesized that a continual analysis of the relationship of cues to reinforcement is being made throughout the learning situation, in acquisition as well as extinction. Cues that initially controlled responding can be attenuated or extinguished as the organism finds better, more correlated, cues associated with reinforcement.

This approach is, in part, derived from the stimulus selection theory of Rescorla and Wagner (1972). In a number of classical conditioning experiments, they showed that the associative strength of a stimulus depends on the existing associative strength of all other concurrent stimuli as well as on its own association with reinforcement. For example, a reinforcer that is perfectly predicted by a cue $(100 \%$ correlation) is unable to sustain conditioning to a novel concurrent cue even though the new cue is itself perfectly correlated with the reinforcer. If the first cue was lowered to a $50 \%$ correlation with the reinforcer, then its associative strength would decline to an appropriate level. If the new cue had a higher correlation with the reinforcer, then it would gain some of the associative strength lost by the first cue. Thus, the total amount of associative strength supported by the reinforcer would remain the same, but it would be split between the two cues.

Rescorla and Wagner attempted to add precision to this idea by stating that changes in associative strength follow the formula:

$$
\Delta \mathrm{V}_{\mathrm{A}}=\alpha_{\mathrm{A}} \mathrm{B}_{\mathrm{i}}\left(\lambda_{\mathrm{i}}-\mathrm{V}_{\mathrm{AX}}\right),
$$


where $\lambda$ represents the asymptote of conditioning supportable by that particular $\mathrm{US}, \mathrm{V}_{\mathrm{AX}}$ is the associative strength of some stimulus compound AX, and $\alpha$ and $B$ are learning-rate parameters for the cues and US, respectively. Conditioning levels of cues cannot stably exceed the level set by the asymptote of conditioning. Conversely, stimulus strength can continue to accrue to correlated stimuli so long as $\mathrm{V}_{\mathrm{AX}}$ has not exceeded $\lambda$.

The present theory argues that the hippocampus and habituative system are engaged whenever a cue loses strength in relation to another cue or when a completely redundant cue is presented. Thus, if a cue was correlated $50 \%$ with reinforcement and then dropped to $40 \%$, the hippocampus would decrease the associative value of the cue to an appropriate level, even though the cue was still being occasionally rewarded. In addition, orienting to redundant stimuli would be inhibited if other cues had appropriated the associative strength supportable by the reinforcer.

Solomon (1977) has shown that damage to the hippocampus disrupts these kinds of processes. Rabbits with bilateral hippocampal damage tended to orient to redundant, novel cues, while control rabbits responded only to the old cue. This provides evidence that hippocampal damage makes the animal less able to appropriately ignore or reduce the strength of very salient stimuli (processed by the reinforcer system).

\section{Hippocampal Involvement in Motivational and Homeostatic Mechanisms}

Given the proposed set of principles of hippocampal function, it would seem logical to assume that the hippocampus is less involved with homeostatic or motivational behaviors than is the amygdala. Whatever changes in these behaviors do occur should result, in the main, from the loss of the proposed functions which are inhibitory in nature. For example, failure to habituate normally to environmental stimuli could increase stress to novel situations. The homeostatic changes resulting from this case would clearly not be due to direct loss of control over them by the hippocampus.

Olds' (1956) study of self-stimulation in rats with chronic electrodes provides an appropriate starting point. Olds found that self-stimulation by rats with electrodes in the hippocampus occurred at significantly lower rates than did self-stimulation by those with electrodes in the amygdala. Furthermore, the lack of a large rewarding effect does not seem to be due to the aversiveness of such stimulation. Finch, Feld, and Babb (1978) showed that the predominant response of hippocampal neurons in cats to mesencephalic and pontine stimulation was inhibitory in nature. In humans, stimulation of the hippocampus has very little of the emotional affect found with amygdalar stimulation. The usual effect produced by damage to the hippocampus in humans is a severe memory and learning deficit (Valenstein, 1973).

Studies investigating changes in motivation and homeostasis after hippocampal damage have been rather negative in their findings (Kaada, Feldman, \& Langfeldt, 1971). Beatty and Schwartzbaum (1968) demonstrated that hippocampal lesions failed to exaggerate, either positively or negatively, the consummatory reactivity to taste properties of solutions. However, septally damaged animals did exhibit such exaggerated reactivity. Similarly, on FI schedules, terminal rates in the fixed interval were enhanced for the septally lesioned, but not the hippocampally lesioned, subjects. Kapp, Gallagher, Holmquist, and Theall (1978) showed that hippocampal stimulation disrupted the response-contingent aspects of passive avoidance but not the noncontingent fear conditioning aspects. Other studies have shown that neither lesions nor stimulation of the hippocampus creates deficits in CER conditioning (Gustaffson, Lidsky, \& Schwartzbaum, 1975; Nadel, 1968).

A number of studies have seemed to show an inhibitory effect of the hippocampus on the pituitaryadrenal system in both animals and humans (Casady \& Taylor, 1976; Rubin, Mandell, \& Crandall, 1966), although the evidence is quite mixed (Micco, McEwen, \& Shein, 1979; van Hartesveldt, 1975; Wilson \& Critchlow, 1973). Some of the confusion possibly stems from a lack of consideration of the learning variables that the hippocampus can affect. For example, Endroczi and Zissak (1962, cited in Bohus, 1975) showed variable effects of hippocampal stimulation on adrenal response, depending on the stimulus frequency. However, when the animals were habituated to the stimulus, the various changes induced previously were not observed. Mixed results have also been obtained with respect to hippocampal involvement in food and water consumption (Jarrard, 1973) and in species-typical behavior in cats (Nonneman \& Kolb, 1974). In the latter study, some affective responses were enhanced and others were diminished.

It should also be noted that autonomic changes induced by hippocampal ablation or stimulation could exert their effect through disruption of septal circuits that act as way stations between the hippocampus and brainstem (Anchel \& Lindsley, 1972; Raisman, 1966). In short, the hippocampus seems to influence homeostasis and motivation to a lesser extent and in a more indirect way than does the amygdala.

\section{Secondary Cue Processing and the Hippocampus}

The hippocampal principles of operation state that, in addition to being involved in the habituation of nonreinforced stimuli, the hippocampus plays an important role in the registration of secondary cues to reinforcement. Secondary cues are those cues which are not in close temporal correlation with the 
occurrence of reinforcement or are nonsalient, background cues. For the moment, we will defer the question of how the hippocampus is involved in two such apparently different functions in order to consider the evidence which supports the assertion of hippocampal involvement in secondary cue processing.

Wickelgren and Isaacson (1963) found that the introduction of a novel, but relatively inconspicuous, neutral stimulus irrelevant to a reinforced running response failed to inhibit the running of hippocampally lesioned rats. The performance of control rats was disrupted by the stimulus, however. Hippocampally lesioned rats, unlike those with amygdalar lesions, were deficient on discrimination tasks that had a low level of cue distinctiveness (Plunkett \& Foulds, 1979). However, the hippocampally lesioned group performed similarly to control groups when the task contained highly distinctive cues. Cue utilization by hippocampally lesioned rats in a complex maze was studied by Winocur and Breckinridge (1973). It was found that these rats could learn a fixed response sequence as well as could cortically lesioned or control rats if highly conspicuous cues were used. When the cues were removed after acquisition, only the performance of the hippocampally lesioned group deteriorated. This confirms the difficulty hippocampally lesioned subjects have in using inconspicuous cues. Similar findings have been obtained in a delayed match-to-sample task (Sinnamon, Freniere, \& Kootz, 1978).

Crowne and Riddell (1969) showed that hippocampectomized rats did not orient to a novel stimulus while performing a dominant discrimination habit, but did do so when not engaged in ongoing behavior. Similar results were obtained with monkeys (Douglas \& Pribram, 1969) and rats (Walker \& Means, 1973). These results are in contrast with amygdalectomized animals, which tend to be highly distracted by irrelevant cues. If hippocampectomized animals are less distractable, then we should see a greater perseveration in on-going tasks and greater sensitivity to primary cue-reinforcer relationships. Devenport (1979, 1980) showed that hippocampally lesioned rats displayed stronger contiguity effects in an operant learning task than did controls.

This deficiency in processing nonsalient cues after hippocampal damage can help explain the puzzling finding in the literature that hippocampectomized rats seem to have generally facilitated performance in active avoidance tasks (Lovely, Grossen, Moot, \& Peterson, 1971). It should be noted that facilitated shuttlebox performance is associated with reduced fear elicited by situational cues other than the CS (McAlister, McAlister, \& Douglas, 1971). Since hippocampectomy was shown to disrupt processing of nonsalient cues, the hippocampally lesioned groups are probably more strongly under the control of the primary cues than are normal rats.
This proposed function is able to account for the O'Keefe and Nadel (1978) hypothesis of hippocampal behavior, which assumes that spatial information or a cognitive map is being analyzed in the hippocampus. Their idea is based on findings that tasks involving spatial components are usually adversely affected by damage to the hippocampus, at least in animals. Such spatial information typically falls into the category of secondary cues, which are processed through the habituative system. In addition, the present theory can handle other aspects of the hippocampal syndrome which provide more difficulty for the cognitive map hypothesis.

The evidence supports the idea that hippocampally lesioned animals do display deficits in processing nonsalient stimuli compared with controls, especially while engaged in some reinforced behavior. How can this function be reconciled with the well-supported finding of hippocampal involvement in habituative processes?

It is argued here that, essentially, hippocampal involvement in secondary cue processing proceeds directly from its capacity to process novel and/or nonreinforced stimuli. The novel stimuli associated with, for example, exploration, are of a more subtle kind than those salient stimuli occurring together with reinforcers processed through the reinforcer system. Therefore, the hippocampus needs to be more sensitive to relatively small changes in the stimulus field in order to respond to and process these stimuli. By definition, secondary cues have a more distant or less correlated relationship with reinforcement and thus, in this respect, share some of the characteristics of the nonreinforced stimuli.

The next question is why the hippocampus, after processing these cues to reinforcement, simply does not habituate them, since they are often temporally removed from the occurrence of the reinforcer. In this case, it is the action of the primary cues which prevents their habituation and preserves their registration as secondary cues to reinforcement. It will be remembered that the primary cues, which are processed through the reinforcer system, acquire some power to activate the reinforcer system on their own. The activation of the reinforcer system, in turn, tends to inhibit habituative processes. Thus, the secondary cues, which are processed through the hippocampus, are preserved from habituation because of the presence of primary cues processed through the reinforcer system. It should be noted that when stimuli are temporally removed from reinforcement, their registration as secondary cues takes place after conditioning has occurred to the primary cues (Gollub, 1977).

The habituative system, by allowing the organism to process the secondary cues, serves to improve the stability and persistence of reinforced behaviors over a longer period of time. Interestingly, the capacity to 
process nonsalient stimuli also gives the organism greater flexibility by allowing shifts in attention to occur to stimuli which would pass unnoticed by the reinforcer system. Thus, depending on the situation, the processing of nonsalient cues can serve two functions.

Metaphorically speaking, the processing differences between the reinforcer system and the habituative system can be compared to two types of tourist. The first type is interested only in the major monuments and landmarks of a city, while the other type devotes all of his/her time to viewing the interesting nooks and crannies. The reinforcer system is like the first type and the habituative system is like the second type.

\section{Discriminative Stimuli and the Hippocampus}

The current theory ascribes specific properties to the secondary cues, namely, that they have no conditioned reinforcing properties. As noted before, in the section on the amygdala, Rizley and Rescorla (1972) showed that the strength of a second-order stimulus was not dependent on the current strength of either the $\mathrm{CS}_{1}$ or the US. The $\mathrm{CS}_{1}$ seemed to have a direct, shared relationship with the US, a relationship that was qualitatively different from that of the $\mathrm{CS}_{2}$ with the US. The primary cues (e.g., $\mathrm{CS}_{1}$ ) are being processed through the amygdala and reinforcer system, which has strong afferent connections to affective areas and also produces affective reactions itself. On the other hand, the secondary cues are processed through the hippocampus, which is less involved with emotional responses. Thus, the secondary cues are, in a sense, divorced from the emotions.

There is a large body of evidence which points out that a conditioned reinforcer and discriminative stimulus are not necessarily the same thing (cf. Gollub, 1977; Morgan \& Firsoff, 1970). Some neurological studies (e.g., Schwartzbaum \& Gay, 1966) have been able to dissociate the affective responses to reinforcers from instrumental responding on operant schedules. It should be mentioned in this regard that many cues on an operant schedule are discriminative stimuli, but not conditioned reinforcers (Williams, 1965).

These observations can shed light on the findings of a number of studies. For example, Winocur and Black (1978) studied the effects of hippocampectomy on passive avoidance performance. After rats were trained to run to a goalbox to obtain food, shock was delivered in the goalbox. Hippocampectomized rats showed a greater deficit in inhibiting their approach behavior than did normal rats, which is the usual finding. The rats were then given a retention test $24 \mathrm{~h}$ later. However, before the retention test for passive avoidance was given, the rats were noncontingently exposed to shock, related stimuli, or neutral stimuli as a reminder of the previous treatment. When the hippocampally lesioned subjects were exposed to shock or related stimuli, they performed the same as controls. Exposure to the neutral stimuli left the deficit unchanged.

Winocur and Bindra (1976) found that the essential difference between the hippocampally lesioned rats and control rats on a passive avoidance task was not the number of shocks they received but the point at which the approach behavior to the food was inhibited (cf. Cogan \& Reeves, 1979). Hippocampals would proceed about two-thirds of the way down the alley before stopping, while controls would stop shortly out of the startbox.

It is well known from behavioral research that the conditioned reinforcing properties of cues at any point in a runway leading to food are directly dependent on the distance of that part of the alley from the food, that is, on the reinforcement gradient (Grice, 1948). This fact, when applied to the above two studies, indicates that the hippocampally lesioned rats are being guided by the primary cues present in such a task but are unable to make use of the secondary cues as the control rats do. The reminder technique used by Winocur and Black involved the presentation of the reinforcer or primary cues, and thus the hippocampally lesioned rats were able to make use of this information and improve their performance.

A further indication that this division of cue processing actually exists is provided by Solomon (1977), who demonstrated that hippocampal damage had no effect on the formation of conditioned inhibitors. This paradigm involves the pairing of a $\mathrm{CS}+$ with reinforcement and a CS - with nonreinforcement. In terms of the present theory, the conditioned inhibitors are being processed through the reinforcer system. The evidence for this statement is based on the finding that they seem to possess negative conditioned reinforcing properties (Terrace, 1971). As was previously noted, the reinforcer system is involved in the acquisition of conditioned reinforcing properties and is unaffected by hippocampal damage.

Given that primary cues and secondary cues have different properties and that the reinforcer system processes the former and the habituative system the latter, what reasons are there for such a division of cue processing? Researchers (cf. Kelleher \& Gollub, 1962) have noted that salient stimuli that are too far removed from the occurrence of reinforcement seem to take on inhibitory qualities. This could create problems for an organism in terms of its ability to carry out long-range strategy to achieve reinforcement. The hippocampus has much less direct involvement in motivational functions than does the amygdala. Thus, it is less affected by such considerations. Although the secondary cues control behavior less strongly than do the primary cues, in the sense that an animal's behavior under secondary cues is more easily disrupted (Lyon \& Millar, 1969), they have the 
advantage of working in more difficult circumstances, allowing the organism to engage in behaviors that will eventually lead to reward.

\section{The Hippocampal Syndrome in Humans}

A fascinating question concerning hippocampal function has been the relative lack of correspondence between the deficits displayed by humans and animals following hippocampal damage. Typically, bilateral damage to the hippocampus in humans seemed to result in an almost total incapacity to learn new information, at least in long-term memory. Shortterm memory remained relatively unimpaired (Talland, 1965). On the other hand, deficits displayed by animals, while considerable, did not approach the level seen in humans. Additionally, the pattern of losses in humans and animals seemed to be different, leading to the possibility that the hippocampus assumed new functions in humans. The present theory contends, however, that there is no appreciable difference in the function of the hippocampus in humans and animals, although humans do process types of information that animals do not.

Before dealing with the specifics of the losses, it will be useful to provide a possible reason for the very extensive nature of the human hippocampal deficit. One of the most striking differences between humans and animals is the qualitatively different nature of the emotional or motivationally significant behaviors in each group. Animals, even primates, have a wide variety of species-specific behaviors in sexual, social, feeding, and drinking response classes, behaviors which are elicited by relatively standard environmental stimuli and which appear in roughly the same form in all normal members of the species. Although sociobiologists (e.g., Morris, 1977) have pointed out that humans also have behavioral patterns that seem to have an innate component, language acquisition perhaps being the prime example, a close examination indicates that, in large part, these response patterns either are present only in infants (e.g., suckling response) or are dependent on basic autonomic or anatomical characteristics (e.g., laterality or licking one's lips because of a reduction in salivation due to fear). In precisely those areas that one sees the most elaborate integrated species-specific behaviors in animals, human behavior shows convincing evidence of great variability. This variability could perhaps be due to the invasion of verbal-symbolic mediation which can create significance in stimuli that have no necessary biological or evolutionary importance or meaning, although the direction of causality is, of course, an open one. For example, rodent sexual behavior is controlled by a precise sequence of stimuli which elicit particular responses, given the appropriate level of hormones. If the correct stimuli are not present or if the particular response to be performed is prevented, then the whole behavior is disrupted. It is hard to think of an equivalent example with regard to human motivated behavior.

We have noted the disruptive effect of amygdalectomy on monkeys' interpretation of social behavior (Thompson et al., 1977). The social signals used by monkeys are not arbitrary but, instead, are fairly invariant across members of the species, for example, threat postures and submissive gestures. This is not the case with humans to anywhere near the same degree. To cite Morris (1977), threats can be expressed in many different ways, which often differ from culture to culture. Most striking is the complete arbitrariness of linguistic symbols. Humans have a profuse variety of languages which can differ quite profoundly from each other. Additionally, linguistic behavior is often temporally removed from direct reinforcing consequences.

Now, it will be remembered that the reinforcer system was assumed to process reinforcing stimuli and primary cues, providing the means for their capacity to evoke species-specific behavior. On the other hand, secondary cues without conditioned reinforcing properties seemed to be processed through the hippocampus and habituative system. If there is a lack of fully integrated species-specific responses, as there seems to be, and if humans possess the capacity for a wide variety of arbitrary, voluntary responses controlled by discriminative stimuli that are not conditioned reinforcers, as is known, then the relative importance of the reinforcer and habituative systems should reflect this fact. That is, the habituative system should be vastly more important relative to the reinforcer system in humans than it is in animals. In mammals, the reinforcer and habituative systems seem to be fairly evenly balanced in terms of their importance. With humans, this balance is gone because of the reduction in species-specific behaviors and because so many cues are discriminative stimuli without emotion-evoking properties.

Thus, it seems clear that destruction of the hippocampus could cause a broader, more severe deficit simply because a greater percentage of information is being processed through it. Animals process much information through the amygdala and reinforcer system, which should remain intact after hippocampal damage. It is now time to examine the exact nature of the deficit in humans, to see if it can be accounted for in terms of the hippocampal principles of operation listed above.

Although earlier studies (e.g., Talland, 1965) indicated an almost total long-term memory deficit for nonmotor tasks, more recent evidence suggests that long-term memory per se is still intact. The deficiencies seem to relate more to retrieval of information from long-term memory than from an incapacity to form a stable memory (Squire \& Slater, 1978; Warrington \& Weiskrantz, 1968). The present theory hypothesizes that one aspect of hippocampal func- 
tion is the processing of secondary cues, either nonsalient or temporally removed from a reinforcing event.

Cermak, Butters, and Moreines (1974) and Cermak and Reale (1978) have suggested that the amnesia effect found with patients with hippocampal damage or with Korsakoff's syndrome (partial damage to the mammillary bodies and other areas believed to be connected with the hippocampus) is due to deficient encoding capacities. Winocur (1979) argues for a related idea, namely, that the deficit is in the retrieval of contextual cues. Although the amnesia patients have the ability to encode verbal material on a semantic, acoustic, or associative basis, they tend to perseverate on one particular encoding dimension in a task (Oscar-Berman, 1973). Butters and Cermak (1975) reported a study by Oscar-Berman and Samuels which indicated that Korsakoff patients seem to attend to fewer stimulus dimensions of the test stimuli than do control subjects. Conversely, it has been shown that such amnesics perform consistently better on paired-associate and free recall tasks when distinctive external cues are used to aid recall. The control subjects, on the other hand, perform effectively with minimal external cuing (Winocur \& Kinsbourne, 1978).

These findings relate to those seen with animals, in which less salient cues were ignored by hippocampally lesioned groups (Wickelgren \& Issacson, 1963; Winocur \& Breckinridge, 1973). It seems that humans with hippocampal damage also display a reduced ability to make use of salient cues. This would make retrieval more difficult in many circumstances, since only those retrieval cues which in some way relate to the encoded dimensions of the target would be useful (Anderson \& Bower, 1974; Tulving, 1976). The extent to which the encoding of the target items is unidimensional or otherwise impoverished reduces the number of interassociations and other retrieval cues which can effectively elicit the item. This deficient encoding is not, however, the whole reason for the hippocampal syndrome.

The hippocampus, according to the present theory, is involved with both the processing of secondary cues and the habituation of nonreinforced stimuli, as noted previously. Thus, the human hippocampal syndrome should provide evidence for deficits in the reduction of the associative strength of stimuli.

Warrington and Weiskrantz (1968) have provided evidence that the severe memory deficit found in humans with hippocampal damage is not due to an inability to form long-term memories, as was initially believed, but instead results from severe interference effects. In the recall tests of word lists, the learning rate for the amnesics was very poor. Recognition of the words was even poorer than recall, which is the reverse of the usual finding with normal subjects. In- terestingly, the amnesics showed a very high intrusion rate, with words from previous lists rather than the most recent list being recalled. In other words, there was an abnormal amount of proactive interference.

Testing the amnesics with cued recall led to much different results. Weiskrantz and Warrington (1970, 1975) have shown that when strong cues for the target words are presented at test, performance of the amnesics can approach that of control subjects. For example, if por is given as a cue for $\mathrm{PORCH}$, then recall of PORCH is quite good for the amnesics as well as for the controls. Paired associate learning performance is similarly improved when the paired associates conform to some semantic and phonetic rule (e.g., CHAIR-FAIR or CHAIR-SEAT). If, however, a new set of response words is given with the old stimulus terms (i.e., the A-B, A-D interference paradigm), the amnesics perform very poorly on the second list.

Additional research has indicated that the deficit on the second paired associate list occurs mainly after the first recall attempt (Warrington \& Weiskrantz, 1978). That is, the first attempt to recall the A-D list revealed a similar deficit in both normal and amnesic subjects, with false positive rates evident. It was on subsequent recall trials that the normal subjects showed substantial improvement, whereas the amnesics remained at nearly the same initial level of performance. This suggests that normal subjects can learn to suppress the intrusions but that the amnesics cannot. High intrusion rates seem to appear when attention is shifted from the processed items. Amnesics can remember items that are kept in STM, but when a distractor task intervenes before recall, intrusion rates from previously learned material increase significantly (Meudell, Butters, \& Montgomery, 1978).

Recognition tasks clearly reveal the inability to suppress previous information. Huppert and Piercy (1976) studied recognition performance on familiar and unfamiliar items and found a high false positive rate with regard to familiar items. Interestingly, amnesics were more accurate in recognition of unfamiliar items than they were of familiar items, unlike the control subjects. Owens and Williams (1980) note that, in recognition tasks, amnesics tend to accept as to-be-remembered items anything which evokes a dominant response because of past usage. Interestingly, patients with amygdalar damage seem to benefit from exposure to previously presented targets and distractors with regard to recognition tasks, which is the opposite of what is found with Korsakoff patients (Andersen, 1978).

How is the present theory able to account for this pattern of results after habituative system damage? It can be noted at the start that the exhibited deficits seem to relate either to the processing of secondary, 
nonsalient cues or to the failure to habituate previously learned responses, deficits that were found in animals with habituative system damage.

There are three major points to consider in attempting to tie together the various results obtained with amnesics. First of all, the habituative system in humans processes a vastly expanded amount of material compared with that of infrahumans. This is because verbal-symbolic material is usually not in close temporal correlation with primary reinforcement and thus is not likely to be processed through the reinforcer system.

Damage to the left hippocampus, in particular, seems to result in verbal processing deficits (Butters \& Cermak, 1975). Considering the ubiquity of such stimuli, it is small wonder that the deficits produced by damage to the habituative system should seem so massive without even considering that many nonsymbolic stimuli will also fall under the category of secondary cues. Amnesics do seem to retain motor and perceptual tasks rather well (Milner, Corkin, \& Tauber, 1968), so that their learning deficit cannot be said to be total. The theory would predict that basic classical conditioning should remain unaffected in amnesics as well, especially with the noncognitive stimuli typically used with animals.

The next two points to be considered narrow the focus of the expected deficit. The amnesics, according to the present theory, should show deficits in encoding or even spontaneously noticing secondary stimulus attributes of a situation. This deficit has important implications, since it has been shown that recognition is worse than recall in amnesics, the reverse of the usual finding with normal subjects. It should be noted that the recognition task typically used in verbal learning is considerably more difficult than many recognition decisions humans make. For example, the subject is asked whether MUSTARD occurred on the last of four lists of words, not whether it is recognized as an English word.

A number of studies have indicated that it is the amount of contextual information attached to the item that is a prime determinant of correct recognition performance (cf. Anderson \& Bower, 1974). For example, Schulman (1967) reported that polysyllabic, low-frequency words were recognized better than shorter words of the same type. The greater amount of distinctive physical information in the longer words aided recognition. Distinctive semantic, contextual, and visual information can also aid recognition in normal subjects (Craik, 1973; Horowitz \& Manelis, 1972).

If we assume that the amnesic has impoverished capacities to encode secondary (contextual) information, it is clear that recognition should suffer. On the other hand, recall is less dependent on a wide variety of attached contextual information and more dependent on organizational and associative factors (Craik,
1973; Mandler, 1967; Underwood, 1969). Thus, recall should not suffer quite as much by an inability to encode along a number of different dimensions.

The second specific point made by the present theory concerns the increased intrusion of previously learned materials in situations in which the response to a stimulus has been changed. It was stated before that the hippocampus and habituative system were involved in all stimulus strength reduction whether or not this occurred in the extinction situation. If this is the case, then it is obvious why previously learned material should have such a powerful interference effect for the amnesics. Any verbal response they have learned in a particular situation tends to be extremely persistent and stable in terms of its associative strength. New material must compete with all this previous material in terms of encoding and retrieval.

Additionally, the new material, since it is encoded with only a few stimulus dimensions, may not be sufficiently distinctive to be discriminable from earlier material. As is well known from Wickens (1970), release from proactive interference is dependent, in large part, on the establishment of some distinguishing characteristic between classes of material, although this process can be implemented at the time of retrieval as well as at encoding in normal subjects. Impoverished encoding or an inability to make use of secondary, nonsalient characteristics may lead to insufficient attributes to afford retrieval of the item from a large pool of possible items. This should be true particularly for recognition decisions.

Thus, we should expect to see not only the failure to habituate or suppress previously learned material but also the inability to distinguish very well among different items in memory. Cued recall can be effective because it does not share the drawbacks of recognition for the amnesic (i.e., the necessity for substantial contextual information) or require the demanding search requirements of free recall.

These various points lead to the conclusion that while habituative system damage in humans leads to a more debilitating deficit than it does in animals, this damage is not due to some totally new function of the habituative system. Instead, it is the result of the increased importance to human behavior of stimuli which tend to have characteristics suited to processing by the habituative system, namely, their relatively distant connection with primary reinforcement and non-species-specific character. Unfortunately for the amnesics, it is precisely this kind of information which is most ubiquitous in human interactions. Thus, their deficit stands out in bold relief.

\section{The Hippocampus and Response Information}

An important line of inquiry into hippocampal function has been initiated by studying hippocampal unit response to simple classical conditioning pro- 
cedures (Berger, Alger, \& Thompson, 1976; Berger \& Thompson, 1978a, 1978b). Units were recorded in the dorsal hippocampus of rabbits while a CS tone paired with air puff to the cornea was presented. Differential responses of neurons were discovered to occur very early in the course of conditioning. This initial response preceded the occurrence of the unconditioned response by approximately $30 \mathrm{msec}$. As training progressed, the neuronal response moved forward in time and preceded the occurrence of the $\mathrm{CR}$, again by about $30 \mathrm{msec}$. The general topography of the neuronal response also appeared to match that of the behavioral response. The truly important finding of these studies lay in the fact that unpaired presentations of the CS and US did not lead to this pattern of neuronal response, although there was some slight activity in response to presentations of the US alone. Thus, the activity of these neurons seems to be directly related to learning variables.

Hoehler and Thompson (1979, 1980), in further investigation of this phenomenon, manipulated certain variables in the classical conditioning procedure. Changes in CS-US interval created changes that were consistent at both the behavioral and neuronal levels. When the CS-US interval was too short to yield behavioral conditioning to the CS (i.e., $50 \mathrm{msec}$ ), neuronal response was also absent. However, behavioral and neuronal responses were evident at 150and 250-msec intervals. When the CS-US interval was shifted from 250 to $500 \mathrm{msec}$, the peak neuronal response moved in tandem with the peak behavioral CR. At the human level, there is also some evidence that neurons in the hippocampus are sensitive to responses, in this case, verbal responses (Halgren, Babb, \& Crandall, 1978). Hippocampal neurons have also been shown to be sensitive to body orientation in space, approach to food and water, and general orienting (O'Keefe \& Dostrovsky, 1971; Ranck, 1973).

As Moore (1979) notes, the puzzling aspect of the animal data is that the hippocampal sensitivity to responses at the neuronal level does not lead to a response deficit after damage to this area. It might also be noted that neither does hippocampectomy disrupt basic classical conditioning. There is not even a discernible short-term loss that might indicate relearning or recovery of the function through other brain areas.

Thus, after damage in just those regions of the hippocampus which receive extensive response information, we see no actual response-related deficits. However, we do see pronounced deficits in stimulus processing capacities. This kind of evidence compels one to believe that the response-related activity of hippocampal neurons is not due to their functioning as the substrate of the CR of other responses, but rather is due to the fact that it serves some purpose with regard to the stimulus-processing capacities of the hippocampus.
Moore (1979) hypothesized that this response information is used to preserve the functional integrity of the CS-US relationship and to provide a means by which irrelevant stimuli can be blocked out. Translated into the context of the present theory, this hypothesis achieves the following form: Response information related to learning is transmitted to hippocampal neurons so that habituation of the stimuli controlling the response can be inhibited. The learned response is probably an ideal way of identifying relevant stimuli for the hippocampus, since in a learning situation there may be any number of stimuli that are occurring at some time during the trial. Although the presence of response information may well play a role in the blocking of redundant stimuli as well, it is harder to conceptualize the mechanism whereby such information could be used for this purpose.

The hypothesis that information about the CR plays a role in the inhibition of habituative processes raises the question of how conditioned inhibitors, which do not necessarily evoke some precise response, can avoid habituation by the hippocampus. The answer, according to the current theory, is clear: Activation of the reinforcer system by the conditioned inhibitor, which has negative conditioned reinforcing properties, inhibits the action of the habituative system. That said, an additional question suggests itself: What relationship does the activation of the reinforcer system have with the transmission of response information to the hippocampus? Although this is a good question, the neuronal evidence is too fragmentary to permit guessing. However, there is an additional phenomenon relevant to this problem, namely, the hippocampal theta wave.

\section{The Hippocampal Theta Wave}

No discussion of hippocampal function can be complete without mention of the role of the hippocampal theta wave, which is a rhythmical slow wave, nearly sinusoidal in character. It varies in frequency between 6 and $12 \mathrm{~Hz}$ in the rat and also has a widely varying amplitude. There are basically two forms of theta waves: one that is sensitive to atropine and one that is atropine resistant. This latter type is associated with behavioral movements (Robinson \& Vanderwolf, 1978; Vanderwolf, 1971).

This EEG pattern has been linked to just about all possible behavioral variables, including arousal, attention, learning, motivation, and motor behavior (cf. Bennett, 1970; Black \& Young, 1972; Nadel \& O'Keefe, 1974). There are distinct species differences in the characteristics of these waves. Rats, cats, and dogs seem to display theta patterns somewhat similar to each other but noticeably different from those found in monkeys and humans (Halgren et al., 1978). One main difference is that theta in monkeys and humans is briefer in duration and occurs less frequently (Brazier, 1972; Crowne \& Radcliff, 1975). 
Arnolds, da Silva, Aitink, and Kamp (1979) and Vanderwolf (1971) have shown that, at least for the rat and the dog, theta waves are basically dependent on the motor activity of the animal, although there is evidence for some type of theta during immobility (cf. Frederickson, Lenig, \& Frederickson, 1980; Winson, 1972). The mobility-related theta waves accompany voluntary, arbitrary movements such as walking, running, climbing, head movements, etc. Steady motor activity is correlated with a lower frequency than occurs at the initiation of movement, but the theta waves themselves continue as long as the movement does, even up to $8 \mathrm{~h}$ (Whishaw \& Vanderwolf, 1970). Thus, the hippocampus receives response-related information not only about the CR, but also about instrumental, voluntary responses. The latter information seems to be transmitted to the hippocampus irrespective of their connection with reinforcement.

Other types of hippocampal theta waves, such as the large, irregular waves, are correlated with behavioral immobility, but interestingly, also appear with species-specific behaviors such as licking, cleaning, drinking, urination, shivering, etc. Black and Young (1972) and Vanderwolf (1971) support a dichotomy, based on this phenomenon, between arbitrary, voluntary responses and consummatory, autonomic behaviors. It is obvious, of course, that motor behavior is occurring in those species-specific behaviors, yet theta waves are not displayed. Thus, the theta is correlated with only certain kinds of motor activity.

Despite the strong correlation between the atropineresistant theta and voluntary movements, many researchers have argued that the theta wave is directly related to attentional or learning variables (cf. Bennett, 1970; Isaacson, 1974), and evidence has been found linking theta with modulation of sensory processing (Fleming \& Bigler, 1974; Komisaruk \& Beyer, 1972). Nadel and O'Keefe (1974) hypothesized that the hippocampus is involved in processing spatial information and that the theta is correlated with movements as the animal moves through space (Hill, 1978).

Crowne and Radcliffe (1975), working with monkeys, have provided evidence for a rather clear dissociation between theta and movement in this animal. Many apparently voluntary movements do not elicit theta in the monkey. On the other hand, theta is not especially correlated with attentional responses to novel stimuli, either. The authors did discover, however, that theta did seem to occur more frequently in the extinction situation. The theta bursts generally occur at the beginning of the cessation of reward, sometimes noncontingently with responses.

As can be seen, the situation with regard to the implications of the theta wave is not settled. Although highly correlated with motor activity in many species, lesions of the hippocampus or septal pacemaker cells which control the theta rhythm have no effect on motor performance per se (Black, 1975). It should be noted that this lack of deficit is exactly what we saw in the unit data on CR performance. However, no learning or motivational variable has much of a correlation, either, with theta.

Crowne and Radcliffe (1975) argue that the theta wave is associated with changes in the valence of stimuli. They hypothesize that this process is closely coordinated with physical movement in the rat but that higher up the phylogenetic scale this correspondence declines. Komisaruk (1977) has put forth a hypothesis that states that the theta rhythm may reflect the organization of sensorimotor processes into sequential patterns. He advances the interesting idea that each theta cycle is composed of discrete periods in which different activities are more probable that at other points in the cycle. For example, Semba and Komisaruk (1978) showed that the performance of an operant response is more probable at the negative peak of the cycle than other times, although there is no invariable correlation between the operant response and the negative peak.

In the present theory, a slightly different approach is taken. It is argued that the occurrence of the theta wave represents a capability of cue processing by the habituative system in certain species. It should be stressed that capability here does not mean that cue processing will necessarily occur when the theta waves occur. However, in the absence of theta waves, cue processing by the habituative system of the normal animal should be greatly reduced or nonexistent. However, cue processing by the reinforcer system should remain. This processing state of the habituative system is perhaps best described by comparing it to cortical EEG. It is well known that, in the awake organism, cortical EEG patterns such as desynchronization are correlated with a broad class of behaviors rather than with any specific behavior. For example, cortical desynchronization is not dependent on movement or learning or motivational factors, even though all of these can occur with it. Instead, it seems to be related to a general capacity to engage in certain activities. Additionally, it should be remembered that EEG patterns can be abolished without necessarily disrupting behavior either at the cortical or the limbic system level (Key \& Bradley, 1959; Vanderwolf \& Vanderwart, 1970). This is a reminder that it is the neurons underlying a particular EEG pattern that are responsible for behaviors, not the electrical activity they emit as a consequence of this.

The presence of hippocampal theta waves in the awake, normal organism indicates a capacity to process cues through the habituative system, a capacity that is not present when hippocampal fast-wave activity is seen. This in no way goes against the finding that in some species motor activity of a certain kind is correlated with theta waves. It is entirely possible for a processing capability to be tied to the occurrence of these particular activities even though 
it may not always be engaged or operative. Similarly, mental concentration is correlated with cortical desynchronization, although desynchronization can occur without mental concentration.

It may be possible to illustrate more precisely the hypothesized workings of the habituative system by analyzing some of the theta-wave-induction literature. Gray (1970) noted that the theta-wave frequency of rats was correlated with different situations. When rats are exploring a novel environment or when they are exposed to frustrative nonreward, the theta frequency is about $7.5-8.5 \mathrm{~Hz}$; when they consume a reward, the frequency falls to $6-7.5 \mathrm{~Hz}$; running is associated with an $8.5-10-\mathrm{Hz}$ frequency. This is consistent with Vanderwolf's findings of theta frequency correlation with degree of activity.

In this study, Gray administered sodium amobarbitol to the rats and measured the effect on septal driving of the theta rhythm. Stumpf (1965) had shown that it was possible to drive the theta rhythm by stimulating the medial septal cells. Lesions to this area blocked the theta rhythm (Donovick, 1968). Gray found that sodium amobarbitol selectively raised the driving threshold for theta at $7.7 \mathrm{~Hz}$ but had little or no effect at other frequencies. It will be noted that $7.7 \mathrm{~Hz}$ falls inside the range that normally accompanies frustrative nonreward and exploration in the rat. Behaviorally, the rats took longer to extinguish a rewarded response.

Since amobarbitol retards extinction and raises the driving threshold of $7.7-\mathrm{Hz}$ theta waves, it is reasonable to assume that artificially producing these theta frequencies during extinction should increase the rate of extinction; this is what Gray found. Additionally, Gray found that amobarbitol administered during acquisition in a partial reinforcement schedule could block the partial reinforcement extinction effect. Conversely, driving the theta rhythm of $7.7 \mathrm{~Hz}$ during acquisition on continuous reinforcement produced a pseudopartial reinforcement extinction effect. Thus, opposite effects are produced by theta driving or blocking, depending on whether they are administered during acquisition or during extinction (cf. Glazer, 1974a, 1974b). Landfield (1977) obtained similar results using active avoidance and passive avoidance.

According to the present theory, it is possible to reconcile these findings with those of Vanderwolf and others. First of all, there can be little doubt that, in the rat, theta activity is correlated with arbitrary, voluntary movement and not with specific learning or motivational variables. However, it should be noted that the $7.7-\mathrm{Hz}$ frequency is also the frequency that occurs in rats placed in a novel environment or in extinction. One of the things that rats do when they are exposed to novel stimuli is to make orienting responses to them. The theta frequency in this instance is probably reflecting the occurrence of the motor aspects of the OR, at least with rats. The fre- quency and amplitude are about right, since these movements are fairly small. In the case of frustrative nonreward, ORs are also occurring. Badia and Defran (1970) showed that omission of an expected US causes ORs instead of CRs to appear.

It is hypothesized that amobarbitol raises the threshold of this particular frequency by suppressing the processing capabilities of the habituative system in the rat. The rat can no longer process the secondary cues and novel stimuli that are usually processed by this system. The loss of this processing capability in turn leads to a diminution of ORs to these stimuli. The increased driving threshold is thus a reflection of the increased threshold for ORs to occur. Amobarbitol can be said to functionally ablate this capacity of the habituative system, at least temporarily. However, the action of the reinforcer system is left intact. This is why amobarbitol affects behavior during frustrative nonreward, but not during acquisition. When it is administered during extinction, it serves to inhibit habituation by inhibiting the processing of the now nonrewarded cues through the habituative system. In addition, ORs to novel nonsalient cues underlying response shift tendencies are also inhibited. It should be emphasized that amobarbitol has this effect because it is directly affecting neuronal response in this system and not because it is changing the theta wave per se.

The converse is true for theta driving in extinction. Here the conditions necessary for cue processing in the habituative system are being artificially induced. Thus, the animal has an increased capacity for processing novel and nonsalient cues in extinction. The response shift tendencies of the hippocampus in a nonreward situation are enhanced.

There remains the problem that when amobarbitol is administered during acquisition, it speeds up rather than retards subsequent extinction. On the other hand, theta driving during acquisition retards later extinction. How does the processing of cues through the habituative system relate to these extinction effects, in brief?

In an instrumental partial reinforcement setting, the normal animal is processing secondary cues through the habituative system in addition to processing primary cues through the reinforcer system. This secondary cue processing is hypothesized to enable the animal to gain increased resistance to extinction in low-reward conditions. This processing occurs because the primary cues are no longer perfectly correlated with reward (cf. Rescorla \& Wagner, 1972). When a prior rewarded response is performed and reinforcement is not received, ORs occur. Since the primary cues are not perfectly predictive, other additional cues tend to get processed to make up the difference between the asymptote of conditioning and the level of cue strength. Since these secondary cues tend to be unprogrammed, at least in any direct way by the experimenter, they are not necessarily on the 
same schedule of reinforcement as the primary cues being processed through the reinforcer system. In fact, they are often on a lower schedule of reinforcement simply because they are more variable and random (e.g., noises, particular postures). Thus, in extinction, it takes longer for these cues to reoccur and be associated with nonreinforcement, which increases the time to extinguish. Notice that the extinction rate is not tied to the sheer number of cues conditioned, but to their schedule of occurrence.

The normal animal has a decreased resistance to extinction under conditions of high reward because there is little chance for additional cue processing to take place through the habituative system. These primary cues are already highly predictive of reward and thus equal the asymptote of conditioning by themselves.

The animal with a disrupted habituative system, on the other hand, tends to have increased resistance to extinction under conditions of high reward because the processing of novel stimuli in extinction is inhibited. Thus, the response shift tendencies induced by such processing in extinction are absent, leading to increased perseverative responding to the correlated primary cues processed through the intact reinforcer system. Such an animal has decreased resistance to extinction under conditions of low reward because the additional cue processing that should have taken place during acquisition never does take place. Since the primary cues are weakly correlated with reinforcement, extinction is fairly rapid.

Theta driving would accentuate the normal workings of the habituative system. Additional cue processing in acquisition would tend to lengthen later extinction. This is due to the longer times needed for the various cues to occur in the presence of nonreinforcement. Thus, a pseudopartial reinforcement effect could be exhibited in a continuous reinforcement schedule. As noted above, theta driving in extinction speeds up extinction because of the enhanced response shift tendencies.

\section{THE SEPTUM IN LEARNING AND MOTIVATION}

\section{Principles of Operation}

The present theory assumes that the septum is a coordinating structure between the reinforcer and habituative systems and has the following properties:

(1) It is composed of two functionally distinct regions-the medial septum and the lateral septum. The medial septum transmits information from the reinforcer system to the hippocampus, while the lateral septum receives information from the hippocampus.

(2) The lateral septum damps the motivational properties of sensory information to avoid having the organism respond too powerfully to their positive or negative qualities. It thus has a reciprocal relationship with the action of the amygdala in controlling organismic responsiveness to motivationally significant stimuli.

(3) The lateral septum decreases the conditioned reinforcing properties of primary cues associated with reinforcement. Through the same process, it inhibits frustrative responses to cues partially reinforced or frustratively nonrewarded.

(4) The medial septum controls processing through the hippocampus and habituative system by means of its pacemaker cells for the theta wave.

(5) The medial septum acts as a relay for information from the reinforcer system to the habituative system. Information about the presence of significant stimuli is relayed through this septal area, which then sends appropriate signals to the hippocampus.

\section{Septal Involvement in Motivation and Homeostasis}

The septum, in its role as intermediary between the reinforcer and habituative systems, necessarily has a strong effect on the processes of both systems. In this section, we will examine its effect on the amygdala and, therefore, the reinforcer system.

The principles of operation indicate that the lateral septum acts as an opponent to amygdalar processes involved in the processing of reinforcers. Since the amygdala tends to augment neural and endocrine response to such stimuli, the septum should counteract the operation of the amygdala, and thus act as a negative feedback loop in restraining an otherwise excessive increase in responsivity.

Abbot and Melzack (1978) demonstrated that lateral septal electrical stimulation, which produced afterdischarges, led to analgesia in rats. Medial septal stimulation did not have this effect, nor did amygdalar stimulation. Septal stimulation also has an analgesic effect in humans (Valenstein, 1973). Lateral septal stimulation has also been shown to suppress aggressiveness and reactivity by almost $80 \%$ from the baseline response in rats. Again, medial stimulation had no such effect (Brayley \& Albert, 1977). Septally lesioned rats reach successively higher levels of discrimination between odorants faster than do controls, which suggests that the septum has an inhibitory effect on the olfactory bulbs (Vom Saal, Hamilton, \& Gandelman, 1975).

Increased reactivity to the taste properties of stimuli is also evident after septal lesions (Beatty \& Schwartzbaum, 1968). Rats with septal lesions completely inhibit drinking when a quinine solution is the only choice available, although they tend to consume more water than controls when it is unadulterated (Gittelson, Donovick, \& Burright, 1969). Although both of the above studies employed total septal lesions, Munoz and Grossman (1980) have shown that 
destruction of medial septal neurons had no significant effect on sucrose or saline preference, making the lateral septum the likely site of the change in reactivity. This does not mean that the medial septum has no influence on any motivational or homeostatic behaviors (cf. de Castro, Stoerzinger, Berkmier, \& Ellen, 1978), but it should be much less than that of the lateral septum.

Septally lesioned rats seem to have exaggerated reactivity to other kinds of stimuli. For example, septally lesioned animals spend less total time in the light than do control animals (Zuromski, Donovick, \& Burright, 1972), display increased activity after shock, although detection thresholds are normal (Lubar, Brener, Deagle, Numan, \& Clemens, 1970), spend more time in contact with conspecifics and display more social behaviors (Booth, Meyer, \& Abrams, 1979), are more aggressive outside of the home territory (Marsden \& Slotnick, 1972), and show a consistent augmentation of defensive behaviors as a result of threat from conspecifics (Blanchard, Blanchard, Lee, \& Nakamura, 1979). This last study showed that the defensive enhancement was not due to an increase in attack behaviors or general reactivity. Amygdalar lesions abolished this enhancement of defensive behaviors.

A similar pattern is displayed in changes of endocrine response to septal lesions. A number of studies have investigated pituitary-adrenal function following lesions of the septum. For example, some researchers have found elevations of plasma corticosterone levels in response to stress after lateral septal lesions (Usher, Lieblich, \& Siegal, 1974). This elevation sometimes occurs to stimuli not found stressful by controls (Uhlir, Seggie, \& Brown, 1974). Basal levels of such hormones tend to remain at normal levels, however. Stimulation of the lateral septum does not show a consistent effect on corticosterone levels (Bouillé \& Baylé, 1975), nor do septal lesions, unlike amygdala lesions, block hypersecretion of ACTH following adrenalectomy (Allen \& Allen, 1975).

It is important to point out that the septum is not viewed in the current theory as a sort of negative amygdala. Although it is directly involved in motivational expression, it does not control the occurrence of species-specific behaviors in the way that the reinforcer system and amygdala do. The septum acts to restrain the augmentation of response produced to significant stimuli rather than to directly control or inhibit species-specific behaviors themselves. Thus, it is not surprising that basal levels of pituitary-adrenal hormones remain relatively unchanged after septal lesions but that the specific response to stressful stimuli is elevated. The lateral septum seems to be part of ascending and descending pathways, which makes it a likely candidate for the motivational and homeo- static changes exhibited after septal lesions (DeFrance, Yoshihara, \& Chronister, 1976).

In the current theory, disruption of species-specific responding after total septal lesions should be the result of unrestrained action by the reinforcer system and/or the loss of function by the habituative system. For example, Fleischer and Slotnick (1978) found that septal lesions prior to mating totally disrupted maternal behavior in female rats: female rats with pups did not nurse them or build nests for them. Retrieval behavior of the mother was extremely persistent, but the pups were rarely gathered into a common location. Female rats septally lesioned after parturition became hyperresponsive and quickly cannibalized their pups. Virgin female rats that had maternal behavior induced in them by the presence of foster pups displayed similar, but less marked, effects.

We saw, with pituitary-adrenal function, that the effects of septal lesions that included the lateral region seem to be focused most strongly on organismic response to significant stimuli, rather than on basal levels of hormones. This finding is echoed in the Fleischer and Slotnick study, since septal lesions disturbed maternal behaviors less severely in virgin female rats than in actual mothers. Presumably, the maternal behaviors are more highly motivated in the actual mothers because the appropriate sensitizing hormones are present.

The action of the amygdala is unrestrained with destruction of the septum. Since the reinforcer system is differentially sensitive to salient, motivationally strong stimuli, it is precisely this response which will be abnormally expressed to the greatest degree. Retrieval behaviors prompted by dispersal of the pups were perseverative in the septally lesioned rats. Again, the authors note that the female rats seemed highly motivated to carry out the retrieval behaviors, but seemed to have difficulty in inhibiting the behavior once it was started. Support for this interpretation is provided by the finding that septally lesioned rats, reinforced with food on FI schedules and in the runway, did not show the typical perseverative effect when trained under satiated conditions (Henke, 1975; cf. also Fallon \& Donovick, 1970).

Destruction of the septum would also be expected to disrupt the functions of the habituative system, since information to and from the hippocampus would be interrupted. Derangement of nest building could be due to a deficit in the processing of spatial cues; the rat is unable to settle on a home territory. The septally lesioned mice in the Marsden and Slotnick study seemed to have such deficits in connection with aggressive behaviors which, in the normal animal, are confined to the home territory.

This analysis points up the fact that total septal lesions are likely to disturb a number of functions in the reinforcer and habituative systems by virtue of 
the intermediary role of the septum. One must agree with Numan (1978) that, in the future, researchers must make distinctions between lesions of the lateral and medial septum in order to obtain theoretically useful results. The present theory makes it clear that these two regions are performing very different functions, which achieve unity only in the sense that they are both involved in the exchange of information between two important stimulus-analyzing systems.

\section{Septal Involvement in the Response \\ to the US in Learning}

If the lateral septum has a reciprocal relationship with the amygdala with regard to reinforcers, this should reflect itself in changes in response to reinforcers used in learning paradigms. Septal rats show a deficit in one-way active avoidance (McCleary, 1966). As Bengellova (1979) demonstrated, this deficit is related to the handling of the animal at the end of each trial in this paradigm. When no handling occurs, the septally lesioned rats show no deficit in acquiring one-way avoidance. In shuttlebox active avoidance tasks, in which handling is not a factor, septal lesions facilitate avoidance learning. The animal's behavior seems to be much more strongly controlled by the primary cues (Sodetz, 1970).

DeNoble and Caplan (1977) studied the effect on septally lesioned rats of response-independent food superimposed on a baseline schedule. Normal animals temporarily increased response rates to noncontingent food on a DRL schedule while decreasing their rates to noncontingent food on DRH schedules. Septal lesions greatly enhanced the acceleration or suppression of responding in these schedules.

Passive avoidance deficits are another common result of lesions to the lateral septum (Hamilton, Kelsey, \& Grossman, 1970). It has been shown that, before the introduction of shock, the approach tendencies of septally lesioned rats are stronger than those of controls. A relative measure of suppression which took this stronger approach tendency to food into account revealed equivalent degrees of response suppression between controls and septally lesioned rats (Kasper-Pandi, Schoel, \& Zysman, 1969).

If septal lesions in animals are causing stronger approach tendencies toward the positive reinforcer in the passive avoidance situation, then we should expect to see greater tolerance of aversive stimulation before the approach response is inhibited. This effect has been found in a number of studies (Poplawsky \& Hoffman, 1979; Schwartzbaum \& Spieth, 1964). The largest difference between the behavior of controls and septally lesioned rats seems to be with moderate levels of shock; in this situation, the normal rats suppress the approach response while the septal rats continue to engage in it. At stronger shock intensities, both groups suppress. In this connection, it should be remembered that septal lesions do not affect de- tection thresholds of shock; the septally lesioned animal presumably experiences the same painful stimulation as the normal animal but has a greater motivation to perform the punished response.

It may be objected that, if septally lesioned animals are reacting more strongly to reinforcers because of the nonrestrained reinforcer system, then it would be just as reasonable to expect them to react strongly to the shock and to suppress the approach response as it would be to expect the opposite. Actually, septal rats do exhibit little or no deficit in passive avoidance if the approach response has not been established before the introduction of shock. In the Schwartzbaum and Spieth study, for example, the septally lesioned rats were no different from controls on the first shocked session if the response had not been well established. Wishart and Mogenson (1970) made a more precise test of this notion by making septal lesions before and after passive avoidance training had been initiated. The lesioned rats that had received postoperative approach training before punishment was introduced did not learn to passively avoid. However, the lesioned group that had received punishment from the start did acquire the passive avoidance response.

These results suggest that septally lesioned animals, rather than having a specific passive avoidance deficit, find it difficult to suppress a previously learned habit. This is not to say that they don't react more strongly to positive reinforcement than do normal animals, but rather that this exaggerated response can occur to negative reinforcement as well. This aspect of septal damage is due to loss of control over the amygdala and reinforcer system. The deficit with regard to inhibiting a previously learned response is due to interruption of habituative system functioning. It will be remembered that damage to the hippocampus caused a very similar syndrome with regard to inhibition of previously learned responses, but not to reactivity to reinforcers.

\section{Cue Processing and the Septum}

According to the current theory, both the medial and lateral areas of the septum are involved in the processing of cues, although in different ways. The medial septum influences the initiation of processing by the hippocampus and habituative system, while the lateral septum receives the output from the hippocampus.

Wetzel, Ott, and Matthies (1977a, 1977b) studied EEG activity in freely moving rats with implanted electrodes in the dorsal hippocampus. Stimulation of $7 \mathrm{~Hz}$ to the medial septum led to the establishment of typical theta waves and behaviorally always resulted in ORs such as sniffing, exploration, and searching. In line with this finding, Semba and Iwahoras (1974) demonstrated that rats with medial septal lesions were less likely than controls to display ORs 
to novel stimuli while engaging in drinking. Evoked activity of single neurons in the hippocampus was studied by Miller and Groves (1977), who compared the neuronal activity of normal rats with that of rats receiving medial septal lesions. In the normal rat, almost half $(41 \%)$ of the hippocampal neurons studied displayed inhibition following peripheral stimulation. This percentage was halved in the rats with medial septal lesions.

With regard to the lateral septum, we would expect to see deficits relating to hippocampal output (i.e., deficits in habituation or extinction). Kohler (1976b) demonstrated that rats with lateral septal lesions, unlike rats with medial septal lesions, displayed impaired habituation of the OR to auditory stimuli. The lateral septal rats also took longer to habituate to the test environment. Thus, medial septal lesions cause diminished cue processing or ORs, while lateral septal lesions prolong ORs, exactly what we would expect from their functions in the present model.

Another possible property of cues is their capacity to act as conditioned reinforcers. The principles of operation predict that septal damage will lead to an augmentation of the conditioned reinforcing properties of primary cues, since, as has been demonstrated, these cues are processed through the amygdala. Carlson, El-Wakil, Standish, \& Ormand (1976) demonstrated that septal lesions increased the appetitive value of a secondary reinforcer associated with food. Septally lesioned rats displayed an enhanced response rate in the last $10 \mathrm{sec}$ of a FI 1-min interval as compared with controls (Ellen \& Powell, 1962). Septally lesioned mice ran significantly faster than controls on reinforced trials but significantly slower on nonreinforced trials (Carlson, Carter, \& Vallante, 1972). Henke (1977) showed that septally lesioned rats displayed a frustration effect after nonreinforced trials that was abolished by lesions of the amygdala.

Septally lesioned animals tested in the runway for food reinforcement display increased resistance to extinction following CRF training but decreased resistance to extinction following partial reinforcement (Henke, 1977). Feldon and Gray (1979) have shown that the lateral septum is the probable site for this effect, as we would expect from the current theory. Medial septal lesions had inconsistent effects.

Lancaster and Johnson (1976) provide supporting evidence for these findings. Rats with lateral or medial septal lesions were studied on various FR schedules. It was found that as a function of increasing food deprivation, the response rates of septally damaged rats increased more rapidly than did those of controls. More importantly, although lateral septal lesions enhanced FR performance and prolonged extinction, medial septal lesions had no such effect. There were no significant differences between the medial septal group and the control animals; how- ever, there was a distinct trend for the medial septal group to have the lowest response rates and to show the lowest FR strain point. Thus, medial and lateral septal lesions display contrasting effects on cue processing, in keeping with their theoretically assigned functions.

\section{Cue Selection and the Septum}

One of the most noted findings with regard to septal damage is that lesioned animals seem to display a pattern of cue selection different from that of normal animals. For example, Dalland (1970) has shown that, instead of using proprioceptive information, septally lesioned rats are more likely than controls to perseverate toward external stimuli in a maze arm. Similar findings were reported by Clody and Carlton (1969) and Thomas (1972). In the latter study, perseveration in a spontaneous alternation test occurred when olfactory and visual cues were placed in conjunction. Placement of these types of cues in opposition to each other eliminated perseveration.

Kratz and Mitchell (1977) showed that the perseveration displayed by septally lesioned rats is not specific to a particular kind of stimulus (i.e., external vs. proprioceptive). Normal and septally lesioned rats were trained on a behavioral chain in which both exteroceptive and response cues were relevant. In extinction, when the two sets of cues were placed in conflict, the septal rats relied mainly on the responseproduced cues while normal rats displayed random preference.

Changes in the nature of cue selection would be expected on the basis of the septal principles of operation. Damage to the lateral septum would be expected to disrupt the habituative output of the hippocampus and to release the amygdala and reinforcer system from inhibition. Hamilton (1969) tested cats with lateral septal lesions on cued active avoidance using several different response measures, that is, jumping on a shelf, one-way jump hurdle, and twoway shuttlebox. Facilitation of two-way avoidance was reported, and there was no difference between septals and controls on the jump hurdle. The septally lesioned cats showed a consistent deficit on the shelfjump task, however.

Hamilton noted that in the latter task the initial probability of the shelf-jumping response, unlike the other two response measures, was not high, even in normal cats. However, the normal cats, after first making escape responses to the shock, eventually came under control of the cue and displayed avoidance. The septal cats learned to make short-latency escape responses but never did come under the control of the CS in this task. In the other two tasks, the response probability was relatively high and the septally lesioned animals seemed, if anything, to come more strongly under the control of the CS. The pat- 
tern of behavior seems to be due to the difficulty septally lesioned animals have in changing control of behavior from one set of cues to another.

Supporting evidence can be found in a number of studies. For example, Ellen, Gillenwater, and Richardson (1977) studied extinction behaviors of septally lesioned rats on different operant schedules, some of which involved noncontingent delivery of food. On contingent schedules such as DRL, FI, FR, and VI, the lesioned group barpressed more during acquisition and extinction, although they were sensitive to the general response contingencies in effect. However, response rates on free-operant testing and on a VT schedule did not show any evidence of enhancement. As the authors note, the necessary factor for overresponding seems to be a contingency between the response and reinforcement. Fewer behaviors can apparently be initiated and maintained by delayed reinforcement, as we would expect from a reinforcer system acting with a disrupted habituative system.

The enhancement of contingent responding after septal damage is most clearly displayed in DRL schedules, which reinforce a low rate of response. Septal animals do particularly poorly on these schedules because they overrespond and delay reinforcement (Braggio \& Ellen, 1976). The addition of cues can facilitate the performance of these animals, but it may do so by changing the essential nature of the schedule. Interestingly, the improved performance with the cue is not maintained after its removal unless it is slowly faded out (Ellen, Dorsett, \& Richardson, 1977). These deficits tie in very well with the cue processing functions of the septum as outlined here.

If cue shift tendencies are reduced after septal damage, we would expect fewer deficits to occur in reversal tasks which require attention to be spread among a number of different cues rather than just on one or two. To the extent that the reinforcer system and amygdala can increase the strength of a few cues, attentional behavior after septal damage should be more tightly circumscribed, since novel cue processing and cue habituation are affected by total septal lesions. Donovick, Burright, and Fink (1979) found that septally lesioned rats were deficient on discrimination tasks that involved the use of newly relevant cues. The lesioned rats failed to attend to such cues, and their behavior did not come under their control. The degree to which this deficit was exhibited depended on the difficulty level of the task: the more difficult the task, the less deficient was the eventual performance (Schwartzbaum \& Donovick, 1968). Easy discrimination reversals apparently cause the most problem for septally lesioned animals (Chin, Donovick, \& Burright, 1976).

Since spatial cues fall into the category of secondary cues processed by the habituative system, total septal lesions should disrupt such behavior as well. Beatty and Carbone (1980) showed that septal lesions caused performance deficits in an eight-armed radial maze. The task involved the sequential choice of each of the eight arms, since reinforcement could be obtained only once in each arm. The addition of external stimuli to make the cue arms distinctive did not help the septally lesioned rats' performance on this complex spatial task. Visual cues did not help improve septal rats' performance in another complex spatial task, the three-table reasoning test (Hermann, Black, Doherty, \& Ellen, 1980).

\section{Septal Coordination Between the \\ Amygdala and Hippocampus}

Although a hypothesis of septal function has been proposed along with hypotheses of amygdalar and hippocampal function, the interrelationships between the three structures have only been discussed tangentially. It is interesting to speculate on the reasons these structures are interconnected in the way that they are. To clarify the discussion, a simplified diagram of some of the interconnections touched upon by the present theory is provided (see Figure 1).

It will be noted that the septum and the hippocampus have very strong afferent and efferent interconnections, that the amygdala has a strong efferent connection with the septum, and that there is only an indirect connection between the amygdala and hippocampus. The present theory provides a basis for exploring these particular interconnections.

The amygdala processes reinforcers and primary cues, and influences the inhibition of habituative processes in the hippocampus to secondary cues and conditioned reinforcers. It seems to do this indirectly, through neurons in the septum. Swanson and Cowan (1979) have shown that the amygdala has efferent connections running from its medial and central portions to the medial septum via the stria terminalis.

Ranck $(1973,1975)$ has studied individual neuronal firing patterns in the septum and hippocampus. $\mathrm{He}$ found two major types of cells in the nuclei of the medial septum: theta cells and tight group cells.

The theta cells fired in the theta rhythm at various times. The tight group cells, however, fired during specific consummatory behaviors. This is important, because the amygdala seems to have an efferent connection to this part of the septum (Brazier, 1972;

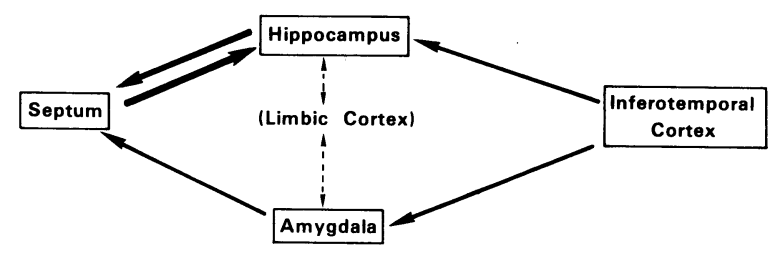

Figure 1. A simplified diagram of some limbic-system interconnections explained in match-mismatch theory. 
Klinger \& Gloor, 1960). It should further be noted that Ranck found cells in the dorsal hippocampus which fired during any consummatory behavior engaged in by the organism. Interestingly, these cells seemed to make no distinction among different consummatory behaviors, firing at the same rate for all of them. Berger and Thompson (1978b) have obtained similar findings for neurons in the medial septum which may drive the hippocampal neurons. Miller and Groves (1977) showed that the medial septum also plays a crucial role in inhibiting neuronal firing of hippocampal neurons after peripheral stimulation.

The septum and hippocampus restore behavioral flexibility in a two-stage process. First, the septum acts to decrease the emotional and motivational differences between reward and nonreward. Secondly, the hippocampus operates to decrease the value of stimuli and responses that are in declining correlation with reinforcement and to initiate cue shift tendencies by processing novel stimuli. The septum needs to be in constant communication with the hippocampus to be able to inhibit cue processing by the hippocampus at appropriate moments. It accomplishes this through its efferent connections to the hippocampus from the medial septum via the dorsal fornix and fimbria and through the efferent fibers from the hippocampus routed to the lateral septum (Swanson \& Cowan, 1977, 1979). Conversely, in order to lift such inhibition, the hippocampus needs to send information to the septum when rewarded stimuli are no longer being reinforced. Thus a strong flow of information between these structures is constantly needed.

It is apparent from the diagram that the amygdala is somewhat isolated from the other two structures, especially when compared with the strong septohippocampal interconnections. This is necessary to protect the functional integrity of the reinforcer and habituative systems. For example, direct input to the amygdala from the hippocampus could disturb the amygdala's capacity to recognize reinforcing events. Direct output from the amygdala to the hippocampus could overwhelm the hippocampus's ability to extinguish uncorrelated stimuli and responses. However, the amygdalar output to the septum is crucial because there must be some way of informing the septum when consummatory behaviors are being performed and reinforcers are being processed in order to suppress unwanted processing by the hippocampus.

One other piece of evidence for the current theory is provided by the interconnections between the inferotemporal cortex and the limbic system. The inferotemporal cortex is involved in high-level visual processing. Also, some aspects of the Kluver-Bucy syndrome of hyperorality and hypersexuality are known to be due to destruction of the inferotemporal cortex. The inferotemporal cortex has efferent connections to the amygdala and hippocampus but not to the septum (Jones \& Mishkin, 1972). This is exactly what is required by the present theory. The amygdala and hippocampus would have to receive high-level visual information in order to know whether a reinforcing stimulus, habituated stimulus, or novel stimulus had been encountered. On the other hand, in the current theory there is no reason why such information would need to go directly to the septum as well.

Considering the complex interconnections of these structures, it may be asked how the organism can sort out the welter of stimuli encountered in a real-life situation and then respond appropriately. Obviously, the organism can make only one response at a time, so the net total of these motivational influences has to be calculated somewhere. Probably the best candidate for such a role is the hypothalamus. The amygdala and septum have strong efferent connections to the hypothalamus, while the hippocampus has strong but more indirect connections (Segal, 1979; Swanson \& Cowan, 1977). In addition, the hypothalamus seems to be essential for the elaboration of fully integrated emotional responses (Bard, 1928; Hess, 1957). It is hypothesized that the hypothalamus receives the various excitatory and inhibitory influences from different areas of the brain and then computes the net result, the bottom line, so to speak. This then determines the nature of the behavioral output.

\section{SUMMARY}

In summary, we can see that the limbic system is composed of two major stimulus processing systems. One system processes salient stimuli such as reinforcers and primary cues, and is strongly tied to motivational factors. The other system processes nonsalient stimuli and either registers them as secondary cues, if there is inhibition of habituation from primary cues, or habituates (extinguishes) them. This division of cue processing is shown to be helpful in explaining certain qualitative differences between cues as well as the dissociation between motivational changes and operant behavior that can often be obtained.

The amygdala is identified as belonging to the system that processes salient stimuli, while the hippocampus is placed in the system that processes and/or habituates nonsalient stimuli. The septum is regarded as a coordinating structure that handles the flow of information between these two structures.

The hypothalamus is viewed as an integrative area that receives the information sent by the limbic system and computes the net motivational result through algebraic summation or subtraction of the different inputs. The reinforcer system and its opponent processes in the septum are assumed to be principally involved in the flow of information to the hypothal- 
amus because of its strong involvement in speciesspecific behavior. The hippocampus is assumed to be more divorced from motivational considerations.

\section{REFERENCES}

Аввотт, F. V., \& Melzack, R. Analgesia produced by stimulation of limbic structures and its relation to epileptiform afterdischarges. Experimental Neurology, 1978, 62, 720-734.

Ackil, I. E., Mellgren, R. L., Halgran, C., \& Frommer, C. Effects of pre-exposure on avoidance learning in rats with hippocampal lesions. Journal of Comparative and Physiological Psychology, 1969, 69, 739-747.

Adey, W. R., Dunlop, C. W., \& Hendrix, C. E. Hippocampal slow waves: Distribution and phase relations in the course of approach learning. AMA Archives of Neurology, 1960, 3, 74-90.

Allen, J. P., \& Allen, C. F. Role of the amygdaloid complexes in the stress induced release of ACTH in the rat. Neuroendocrinology, 1974, 15, 220-230.

Allen, J. P., \& Allen, C. F. Amygdalar participation in tonic ACTH secretion in the rat. Neuroendocrinology, 1975, 19, 115-125.

AnChel, H., \& Lindsley, D. B. Differentiation of two reticulohypothalamic systems regulating hippocampal activity. Electroencephalography and Clinical Neurophysiology, 1972, 32, 209-226.

Andersen, R. Cognitive changes after amygdalotomy. Neuropsychologia, 1978, 16, 439-451.

Anderson, J. R., \& Bower, G. H. A propositional theory of recognition memory. Memory \& Cognition, 1974, 2, 406-412.

Arnolds, D. E. A. T., da Silva, F. H. L., Aitink, I. W., \& KAMP, A. Hippocampal EEG and behavior in dog: I. Hippocampal EEG correlates of gross motor behavior. Electroencephalography and Clinical Neurophysiology, 1979, 46, 552-570.

Aronson, L. R., \& Cooper, M. L. Amygdaloid hypersexuality in male cats re-examined. Physiology \& Behavior, 1979, 22, 257-265.

Badia, P., \& Defran, R. H. Orienting responses and GSR conditioning: A dilemma. Psychological Review, 1970, 77, 171-181.

BARD, P. A. Diencephalic mechanism for the expression of rage with specific reference to the sympathetic nervous system. American Journal of Physiology, 1928, 84, 490-515.

BARRETt, T. W. Studies of the function of the amygdaloid complex in Macaca mulatta. Neuropsychologia, 1969, 7, 1-12.

BassetT, J. R., Cairncross, K. D., \& King, M. G. Parameters of novelty, shock predictability, and response contingency in corticosterone release in the rat. Physiology \& Behavior, 1973, 10, 901-907.

BeatTy, W. W., \& Carbone, C. P. Septal lesions, intramaze cues, and spatial behavior in rats. Physiology \& Behavior, 1980, 24, 675-678.

Beatty, W. W., \& Schwartzbaum, J. S. Commonality and specificity of behavioral dysfunction following septal and hippocampal lesions in rats. Journal of Comparative and Physiological Psychology, 1968, 66, 60-68.

Becker, J. T., \& Olton, D. S. Object discrimination by rats: The role of frontal and hippocampal systems in retention and reversal. Physiology \& Behavior, 1980, 24, 33-38.

BeLluzi, J. D. Long lasting effects of cholinergic stimulation of the amygdaloid complex in the rat. Journal of Comparative and Physiological Psychology, 1972, 80, 269-282.

Bengellova, W. A. Elimination of the septal deficit in one-way active avoidance. Physiology \& Behavior, 1979, 22, 615-619.

BENNETT, T. L. Hippocampal EEG correlates of behavior. Electroencephalography and Clinical Neurophysiology, 1970, 28, 17-23.

Berger, T. W., Alger, B., \& Thompson, R. F. Neuronal substrate of classical conditioning in the hippocampus. Science, $1976,192,483-485$.
Berger, T. W., \& Thompson, R. F. Neuronal plasticity in the limbic system during classical conditioning of the rabbit nictitating membrane response I. The hippocampus. Brain Research, 1978, 145, 323-346. (a)

Berger, T. W., \& Thompson, R. F. Neuronal plasticity in the limbic system during classical conditioning of the rabbit nictitating membrane response II. Septum and mammillary bodies. Brain Research, 1978, 156, 293-314. (b)

Bindra, D. A unified account of classical conditioning and operant training. In A. H. Black \& W. F. Prokasy (Eds.), Classical conditioning II: Current theory and research. New York: Appleton, 1972.

BLACK, A. H. Hippocampal electrical activity and behavior. In R. L. Isaacson \& K. H. Pribram (Eds.), The hippocampus (Vol. 2): Neurophysiology and behavior. New York: Plenum, 1975.

Black, A. H., \& Young, G. A. Constraints on the operant conditioning of drinking. In R. M. Gilbert \& J. R. Millenson (Eds.), Reinforcement: Behavior analysis. New York: Academic Press, 1972.

Blanchard, D. C., Blanchard, R. J., Lee, E. M., \& Fukunaga, K. K. Movement arrest and the hippocampus. Physiological Psychology, 1977, 5, 331-335.

BlanchaRd, D. C., BlanChard, R. J., Lee, E. M., \& Nakamura, S. Defensive behavior in rats following septal and septalamygdala lesions. Journal of Comparative and Physiological Psychology, 1979, 93, 378-390.

Blanchard, R. J., Kelley, M. J., \& Blanchard, D. L. Defensive reactions and exploratory behavior in rats. Journal of Comparative and Physiological Psychology, 1974, 87, 1129-1133.

Boнus, B. The hippocampus and the pituitary-adrenal system hormones. In R. L. Isaacson \& K. H. Pribram (Eds.), The hippocampus (Vol. 1): Structure and development. New York: Plenum, 1975.

Bolles, R. C. The avoidance learning problem. In G. H. Bower (Ed.), The psychology of learning and motivation (Vol. 6). New York: Academic Press, 1972.

Booth, C. L., Meyer, P. M., \& Abrams, J. Changes in social behavior of mice with septal lesions. Physiology \& Behavior, 1979, 22, 931-937.

Bouillé, C., \& BAylé, J. D. Effects of limbic stimulations or lesions on basal and stress induced hypothalamic-pituitaryadrenocortical activity in the pigeon. Neuroendocrinology, 1973, 13, 264-271.

BouILLÉ, C., \& BAYLÉ, J. D. Influence of septal nuclei on basal pituitary-adrenocortical function in birds. Neuroendocrinology, 1975, 18, 281-289.

Braggio, J. T., \& Ellen, P. Cued DRL training: Effect on the performance of lesion induced overresponding. Journal of Comparative and Physiological Psychology, 1976, 90, 694-703.

Brayley, K. N., \& AlberT, D. J. Suppression of VMH lesion induced reactivity and aggressiveness in the rat by stimulation of lateral septum but not medial septum or cingulate cortex. Journal of Comparative and Physiological Psychology, 1977, 91, 290-299.

Brazie R, M. A. B. The human amygdala. In B. Eleftheriou (Ed.), The neurobiology of the amygdala. New York: Plenum, 1972.

Bronson, F. H. Pheromonal influences on mammalian reproduction. In M. Diamond (Ed.), Perspectives in reproduction and sexual behavior. Bloomington: Indiana University Press, 1968.

Brown, P. L., \& Jenkins, H. M. Autoshaping of the pigeon's keypeck. Journal of the Experimental Analysis of Behavior, 1968, 11, 1-8.

Bunnell, B. N., Sodetz, F. J., \& Shalloway, D. I. Amygdaloid lesions and social behavior in the golden hamster. Physiology \& Behavior, 1970, 5, 153-157.

Burt, G. S., \& Smotherman, W. P. Amygdalectomy induced deficits in conditioned taste aversion: Possible pituitary-adrenal involvement. Physiology \& Behavior, 1980, 24, 651-655.

Bush, D. F., Lovely, R. H., \& Pagano, R. R. Injection of ACTH induces recovery from shuttle box avoidance deficits in 
rats with amygdaloid lesions. Journal of Comparative and Physiological Psychology, 1973, 83, 168-172.

ButTers, N., \& Cermak, L. Some analyses of amnesic syndromes in brain damaged patients. In R. L. Isaacson \& K. H. Pribram (Eds.), The hippocampus (Vol. 2): Neurophysiology and behavior. New York: Plenum, 1975.

Carlson, N. R., Carter, E. N., \& Vallente, M. Runway alternation and discrimination of mice with limbic lesions. Journal of Comparative and Physiological Psychology, 1972, 78, $91-100$.

Carlson, N. R., El-Wakil, F. W., Standish, L. J., \& Ormand, D. L. DRL performance, extinction, and secondary reinforcement: Role of appetitive value of food in mice with septal lesions. Journal of Comparative and Physiological Psychology, 1976, 90, 780-789.

Casady, R. L., \& TAYlor, A. N. Effect of electrical stimulation of the hippocampus upon corticosteroid levels in the freely behaving non-stressed rat. Neuroendocrinology, 1976, 20, 68-75.

Cermak, L. S., Butters, N., \& Moreines, J. Some analysis of the verbal encoding deficit of alcoholic Korsakoff patients. Brain and Language, 1974, 2, 141-150.

Cermak, L., \& Reale, L. Depth of processing and retention of words by alcoholic Korsakoff patients. Journal of Experimental Psychology: Human Learning and Memory, 1978, 4, 165-174.

Chin, T., Donovick, P. J., \& Burright, R. G. Septal lesions in rats produce reversal deficits in a simultaneous visual discrimination. Journal of Comparative and Physiological Psychology, 1976, 90, 1133-1143.

Clody, D. E., \& Carlton, D. L. Behavioral effects of lesions of the medial septum of rats. Journal of Comparative and Physiological Psychology, 1969, 67, 344-351.

Cogan, D. C., \& Reeves, J. L. Passive avoidance learning in hippocampectomized rats under different shock and intertrial interval conditions. Physiology \& Behavior, 1979, 22, 1115-1121.

Cohen, D. H. The neural pathways and informational flow mediating a conditioned autonomic response. In L. V. DiCara (Ed.), Limbic and autonomic nervous systems research. New York: Plenum, 1974.

CoHen, D. H. Involvement of the avian amygdalar homologue (archistriatum posterior and mediale) in defensively conditioned heart rate change. Journal of Comparative Neurology, 1975, 160, 13-36.

Coover, G. D., Goldman, L., \& Levine, S. Plasma corticosterone increases produced by extinction of operant behavior in rats. Physiology \& Behavior, 1971, 6, 261-263.

Coover, G. D., Ursin, H., \& Levine, S. Plasma corticosterone levels during active avoidance learning in rats. Journal of Comparative and Physiological Psychology, 1973, 82, 170-174.

CRAIK, F. I. M. A levels of analysis view of memory. In P. Pliner, L. Kramer, \& M. Alloway (Eds.), Communication and affect: Language and thought. New York: Academic Press, 1973.

Crosby, E. C., \& Humphrey, T. Studies of the vertebrate telencephalon II. The nuclear pattern of the anterior olfactory nucleus, tuberculum olfactorium and amygdaloid complex in adult man. Journal of Comparative Neurology, 1941, 74, 309-352.

Crowne, D. P., \& RAdcliffe, D. C. Some characteristics and functional relations of the electrical activity of the primate hippocampus and hypotheses of hippocampal function. In R. D. Isaacson \& K. H. Pribram (Eds.), The hippocampus (Vol. 2): Neurophysiology and behavior. New York: Plenum, 1975.

Crowne, D. P., \& Riddell, W. I. Hippocampal lesions and the cardiac component of the orienting response in the rat. Journal of Comparative and Physiological Psychology, 1969, 69, 748-753.

Czech, D. A. Effects of amygdalar lesions on eating and drinking and saline preference in the rat. Physiology \& Behavior, 1973, 10, 821-823.

Dalland, T. Response and stimulus perseveration in rats with septal and dorsal hippocampal lesions. Journal of Comparative and Physiological Psychology, 1970, 71, 114-118.
Dallman, M. F., \& Jones, M. T. Corticosteroid feedback control of ACTH secretion on subsequent stress response in the rat. Endocrinology, 1973, 92, 1367-1375.

DALY, D. Ictal affect. American Journal of Psychiatry, 1958, 115, 97-108.

Davis, H., Memmott, J., McFadden, L., \& Levine, S. Pituitaryadrenal activity under different appetitive extinction procedures. Physiology \& Behavior, 1976, 17, 687-690.

DeCastro, J. M., Stoerzinger, A., Berkmier, D., \& Ellen, P. Medial septal lesions: Disruptions of microregulatory patterns and circadian rhythmicity in rats. Journal of Comparative and Physiological Psychology, 1978, 92, 71-84.

DeFrance, J. F., Yoshihara, H., \& Chronister, R. B. Electrophysiological studies of the septal nuclei: The lateral septal region. Experimental Neurology, 1976, 53, 399-419.

Dember, W. N. Response by the rat to environmental change. Journal of Comparative and Physiological Psychology, 1956, 49, 93-95.

Denenberg, V. H., \& Haltmeyer, G. S. Test of the monotonicity hypothesis concerning infantile stimulation and emotional reactivity. Journal of Comparative and Physiological Psychology, 1967, 63, 394-396.

DeNoble, V., \& Caplan, M. Enhanced response acceleration or suppression produced by response independent food presentations in rats with septal lesions. Journal of Comparative and Physiological Psychology, 1977, 91, 107-119.

DevenPort, L. D. Superstitious bar pressing in hippocampal and septal rats. Science, 1979, 205, 721-723.

Devenport, L. D. Response-reinforcer relations and the hippocampus. Behavioral and Neural Biology, 1980, 24, 105-110.

Donovick, P. J. Effects of localized septal lesions in hippocampal EEG activity and behavior in rats. Journal of Comparative and Physiological Psychology, 1968, 66, 569-578.

Donovick, P. J., Burright, R. G., \& Fink, E. A. Discrimination behavior of rats with septal lesions in a cue addition-deletion paradigm. Physiology \& Behavior, 1979, 22, 125-131.

Douglas, R. J. The hippocampus and behavior. Psychological Bulletin, 1967, 67, 416-442.

Douglas, R. J. Pavlovian conditioning and the brain. In R. Boakes \& M. Halliday (Eds.), Inhibition and learning. London: Academic Press, 1972.

Douglas, R. J. The development of hippocampal function: Implications for theory and therapy. In R. L. Isaacson \& K. H. Pribram (Eds.), The hippocampus (Vol. 2): Neurophysiology and behavior. New York: Plenum, 1975.

Douglas, R. J., Barrett, T. W., Pribram, K. H., \& Cerny, M. C. Limbic lesions and error reduction. Journal of Comparative and Physiological Psychology, 1969, 68, 437-441.

Douglas, R. J., \& Pribram, K. H. Learning and limbic lesions. Neuropsychologia, 1966, 4, 197-220.

Douglas, R. J., \& Pribram, K. H. Distraction and habituation in monkeys with limbic lesions. Journal of Comparative and Physiological Psychology, 1969, 69, 473-480.

Downe R, J. L. Changes in visual gnostic functions and emotional behavior following unilateral temporal pole damage in the 'split brain' monkey. Nature, 1961, 191, 50-51.

Dreifuss, J. J., Murphy, J. T., \& Gloor, P. Contrasting effects of two identified amygdaloid efferent pathways in single hypothalamic neurons. Journal of Neurophysiology, 1968, 31, 237248.

Dunham, P. The nature of reinforcing stimuli. In J. R. Staddon \& W. K. Honig (Eds.), The handbook of operant behavior. New York: Appleton, 1977.

EgGER, M. D. Responses of hypothalamic neurons to electrical stimulation in the amygdala and the hypothalamus. Electroencephalography and Clinical Neurophysiology, 1967, 23, 6-15.

Ehle, A. L., Mason, J. W., \& Pennington, L. L. Plasma growth hormone and cortisol changes following limbic stimulation in conscious monkeys. Neuroendocrinology, 1977, 23, 52-66. 
Eleftheriou, B. (Ed.) The neurobiology of the amygdala. New York: Plenum, 1972.

Eleftheriou, B., Zolovick, A. J., \& Norman, R. L. Effects of amygdaloid lesions on plasma and pituitary levels of luteinizing hormone in the male deermouse. Journal of Endocrinology, $1967,38,469-474$.

Ellen, P., Dorsett, P. G., \& Richardson, W. K. The effect of cue fading on the DRL performance of septal and normal rats. Physiological Psychology, 1977, 5, 469-476.

Ellen, P., Gillenwater, G. E., \& Richardson, W. K. Extinction of responding by septal and normal rats following acquisition under four schedules of reinforcement. Physiology \& Behavior, 1977, 18, 609-615.

Ellen, P., \& Powell, E. W. Effects of septal lesions on behavior generated by positive reinforcement. Experimental Neurology, $1962,6,1-11$.

Ellen, P., \& Wilson, A. S. Perseveration in the rat following hippocampal lesions. Experimental Neurology, 1963, 8, 310-317.

Fallon, D., \& Donovick, P. J. Low resistance to extinction in rats with septal lesions under inappropriate motivation. Journal of Comparative and Physiological Psychology, 1970, 73, 150-156.

Feldon, J., \& Gray, J. A. Effects of medial and lateral septal lesions on the partial reinforcement extinction effect at short intertrial intervals. Quarterly Journal of Experimental Psychology, 1979, 31, 675-690.

Finch, D. M., FELD, R. E., \& BABB, T. L. Effects of mesencephalic and pontine electrical stimulation on hippocampal neuronal activity in drug free cat. Experimental Neurology, 1978, 61, 318-336.

Fitzsimmons, J. T. Thirst. Physiological Reviews, 1972, 52, 468-561.

Fleischer, S., \& Slotnick, B. M. Disruption of maternal behavior in rats with lesions of the septal area. Physiology \& Behavior, 1978, 21, 189-200.

Fleming, D. E., \& Bigler, E. V. Relationship between photically evoked after discharge occurrence and hippocampal EEG rhythms in restrained and unrestrained albino rats. Physiology \& Behavior, 1974, 13, 757-761.

Frederickson, C. J., Lenig, R. B., \& Frederickson, M. H. Hippocampal RSA in cats during cued and noncued delayed response performance. Behavioral and Neural Biology, 1980, 28, 383-391.

Fried, P. A. Septum and behavior: A review. Psychological Bulletin, 1972, 78, 292-310.

Gibions, J. L., \& McHugh, P. R. Plasma cortisol and depressive illness. Journal of Psychiatric Research, 1962, 1, 162-171.

GIRGIS, M. K. The distribution of acetylcholinesterase enzymes in the amygdala and its role in aggressive behavior. In B. Eleftheriou (Ed.), The neurobiology of the amygdala. New York: Plenum, 1972.

Gittelson, P. J., Donovick, P. J., \& Burright, R. G. Facilitation of passive avoidance acquisition in rats with septal lesions. Psychonomic Science, 1969, 17, 242-243.

Glaze R, H. I. Instrumental conditioning of hippocampal theta and subsequent response persistence. Journal of Comparative and Physiological Psychology, 1974, 80, 267-273. (a)

GLAzE R, H. I. Instrumental response persistence following induction of hippocampal theta frequency during fixed ratio responding in rats. Journal of Comparative and Physiological Psychology, 1974, 86, 1156-1162. (b)

GLOoR, P. Temporal lobe epilepsy: Its possible contribution to the understanding of the functional significance of the amygdala and of its interaction with neocortical temporal mechanisms. In B. Eleftheriou (Ed.), The neurobiology of the amygdala. New York: Plenum, 1972.

Goddard, G. V. Functions of the amygdala. Psychological Bulletin, 1964, 62, 89-109.

Gollub, L. Conditioned reinforcement: Schedule effects. In W. K. Honig \& J. E. R. Staddon (Eds.), Handbook of operant behavior. New York: Appleton, 1977.

Goomas, D. T., Hamm, C., \& Skinner, J. Runway performance of amygdalectomized rats: Magnitude of reinforcement and delay of food reward. Physiological Psychology, 1980, 8, 97-100.

Gray, J. A. Sodium amobarbitol, the hippocampal theta frequency, and the partial reinforcement effect. Psychological Review, 1970, 77, 465-480.

Green, J. D., \& Machne, X. Unit activity of rabbit hippocampus. American Journal of Physiology, 1955, 181, 219-221.

GRICE, G. R. The relation of secondary reinforcement to delayed reward in visual discrimination learning. Journal of Experimental Psychology, 1948, 38, 1-16.

Grossman, S. P. Behavioral effects of chemical stimulation of the ventral amygdala. Journal of Comparative and Physiological Psychology, 1964, 57, 29-36.

Grossman, S. P. The role of the amygdala in escape-avoidance behaviors. In B. Eleftheriou (Ed.), The neurobiology of the amygdala. New York: Plenum, 1972.

Gustaffson, J. W., Lidsky, T. I., \& Schwartzbaum, T. S. Effects of hippocampal stimulation on acquisition, extinction, and generalization of conditioned suppression in the rat. Journal of Comparative and Physiological Psychology, 1975, 85, 11361148.

Guth, S., Seward, J. P., \& Levine, S. Differential manipulation of passive avoidance by exogenous ACTH. Hormones and Behavior, 1971, 2, 127-138.

Halgren, E., Babb, T. L., \& Crandall, P. H. Activity of human hippocampal formation and amygdala neurons during memory testing. Electroencephalography and Clinical Neurophysiology, 1978, 45, 585-601.

HAmilton, L. W. Active avoidance impairment following septal lesions in rats. Journal of Comparative and Physiological Psychology, 1969, 69, 420-427.

Hamilton, L. W., Kelsey, J. E., \& Grossman, S. P. Variations in behavioral inhibition following different septal lesions in rats. Journal of Comparative and Physiological Psychology, 1970, 70, 79-86.

Hanson, J. D., Larson, M. E., \& Snowden, C. T. The effects of control over high intensity noise on plasma cortisol levels in rhesus monkeys. Behavioral Biology, 1976, 16, 333-340.

Henke, P. G. Effects of reinforcement omission on rats with lesions in the amygdala. Journal of Comparative and Physiological Psychology, 1973, 84, 187-193.

Henke, P. G. Septal lesions and the extinction of incentive motivation. Physiology \& Behavior, 1975, 15, 537-542.

Henke, P. G. Dissociation of the frustration effect and the partial reinforcement extinction effect after limbic lesions in rats. Journal of Comparative and Physiological Psychology, 1977, 91, 1032-1038.

Henke, P. G. The amygdala and restraint ulcers in rats. Journal of Comparative and Physiological Psychology, 1980, 94, 313-323.

Hennesy, J. W., King, M. G., McClure, T. A., \& Levine, S. Uncertainty, as defined by the contingency between environmental events and the adrenocortical response of the rat to electric shock. Journal of Comparative and Physiological Psychology, 1977, 91, 1447-1460.

Hennesy, J. W., Levin, R., \& Levine, S. The influence of experimental factors and gonadal hormones on the pituitaryadrenal response of the mouse to novelty and electric shock. Journal of Comparative and Physiological Psychology, 1977, 91, 770-777.

Hennesy, J. W., \& Levine, S. Stress arousal and the pituitaryadrenal system: A psychoendocrine hypothesis. In J. M. Sprague \& A. Epstein (Eds.), Progress in psychobiology and physiological psychology (Vol. 8). New York: Academic Press, 1979.

Hennesy, M. B., \& Levine, S. Effects of various habituation procedures on pituitary-adrenal responsiveness in the mouse. Physiology \& Behavior, 1977, 18, 799-802.

Herrman, T., Black, A. H., Doherty, D., \& Ellen, P. Visual cues fail to attenuate deficits on a spatial integration task following septal or fornical damage. Physiological Psychology, 1980, 8, 29-32.

Hess, W. R. The functional organization of the diencephalon. New York: Grune \& Stratton, 1957.

Hill, A. J. First occurrence of hippocampal spatial firing in a 
new environment. Experimental Neurology, 1978, 62, 282-307.

Hilton, M., \& Zbrozyna, A. Defense reaction from the amygdala and its afferent and efferent connections. Journal of Physiology, $1963,165,160-173$.

Hoelher, F. K., \& Thompson, R. F. The effect of temporal single alternation on learned increases in hippocampal unit activity in classical conditioning of the rabbit nictitating membrane response. Physiological Psychology, 1979, 7, 345-351.

Hoenle R, F. K., \& Thompson, R. F. Effect of the interstimulus (CS-UCS) interval on hippocampal unit activity during classical conditioning of the nictitating membrane response of the rabbit (Oryctolagus cuniculus). Journal of Comparative and Physiological Psychology, 1980, 94, 201-215.

Holmes, J. E., \& EgAN, K. Electrical activity of the cat amygdala during sexual behavior. Physiology \& Behavior, 1973, 10, 863867.

Horowitz, L. M., \& Manelis, L. Toward a theory of redintegrative memory: Adjective-noun phrases. In G. H. Bower (Ed.), The psychology of learning and motivation (Vol. 6). New York: Academic Press, 1972.

Horvath, F. E. Effect of basolateral amygdalectomy on three types of avoidance behavior in cats. Journal of Comparative and Physiological Psychology, 1963, 56, 380-389.

Hughes, R. J., \& ANDy, O. J. The human amygdala II. Neurophysiological correlates of olfactory perception before and after amygdalotomy. Electroencephalography and Clinical Neurophysiology, 1979, 46, 444-45i.

Huppert, F. A., \& Piercy, M. Recognition memory in amnesic patients: Effect of temporal context and familiarity of material. Cortex, 1976, 12, 3-30.

IsAaCSON, R. L. The limbic system. New York: Plenum, 1974.

IsaAcson, R. L., \& McClearn, G. E. The influence of brain damage on locomotor behavior of mice selectively bred for high or low activity in the open field. Brain Research, 1978, 150, 559-567.

IsaAcson, R. L., \& Pribram, K. H. (EDs.), The hippocampus (Vol. 2): Neurophysiology and behavior. New York: Plenum, 1975.

IsEROFF, A. Limited recovery of spontaneous alternation after extensive hippocampal damage. Experimental Neurology, 1979, 64, 284-294.

Iuvone, P. M., \& van Hartesveldt, C. Diurnal locomotor activity in rats: Effects of hippocampal ablation and adrenalectomy. Behavioral Biology, 1977, 19, 228-237.

JACoBs, B. L., \& McGinty, D. J. Participation of the amygdala in complex stimulus recognition and behavioral inhibition: Evidence from unit studies. Brain Research, 1972, 36, 431-436.

JARrard, L. E. The hippocampus and motivation. Psychological Bulletin, 1973, 79, 1-12.

Jenkins, H. M., \& Moore, B. M. The form of the autoshaped response with food or water reinforcers. Journal of the Experimental Analysis of Behavior, 1973, 20, 163-181.

Jones, B., \& Mishinin, M. Limbic lesions and the problem of stimulus-reinforcer associations. Experimental Neurology, 1972, 36, 362-377.

KAADA, B. R. Stimulation and regional ablation of the amygdaloid complex with reference to functional representations. In B. Eleftheriou (Ed.), The neurobiology of the amygdala. New York: Plenum, 1972.

KaAda, B. R., Feldman, R. S., \& Langfeldt, T. Failure to modulate autonomic reflex discharge by hippocampal stimulation in rabbits. Physiology \& Behavior, 1971, 7, 225-231.

Kamin, L. J. Predictability, surprise, attention, and conditioning. In B. A. Campbell \& R. M. Church (Eds.), Punishment and aversive behavior. New York: Appleton, 1969.

Kapp, B. S., Gallagher, M., Holmquist, B. K., \& Theall, C. L. Retrograde amnesia and hippocampal stimulation: Dependence upon the nature of associations found during conditioning. Behavioral Biology, 1978, 24, 1-23.

Kasper-PAndi, P., Schoel, W. M., \& Zysman, M. Motivation and response strength in passive avoidance deficits of septal lesioned rats. Physiology \& Behavior, 1969, 4, 815-822.

Kelleher, R. T., \& Fry, W. Stimulus functions in chained fixed interval schedules. Journal of the Experimental Analysis of Behavior, 1962, 5, 543-597.

Kelleher, R. T., \& Gollub, L. A review of positive conditioned reinforcement. Journal of the Experimental Analysis of Behavior, 1962, 5, 543-597.

Kellicut, M. H., \& Schwartzbaum, J. S. Formation of a conditioned emotional response (CER) following lesions of the amygdaloid complex in rats. Psychological Reports, 1963, 12, 351-358.

Key, B. J., \& Bradley, P. B. The effect of drugs on conditional arousal responses. Electroencephalography and Clinical Neurophysiology, 1959, 11, 841 .

KilleEN, P. Reinforcement, frequency and contingency as factors in fixed-ratio behavior. Journal of the Experimental Analysis of Behavior, 1969, 12, 391-395.

Kimble, D. P. Hippocampus and internal inhibition. Psychological Bulletin, 1968, 70, 285-295.

Kirkby, R. J., Stein, D. G., Kimble, R. T., \& Kimble, D. P. Effects of hippocampal lesions and duration of sensory input on spontaneous alternation. Journal of Comparative and Physiological Psychology, 1967, 64, 342-345.

KLING, A. The effects of amygdalectomy and testosterone on sexual behavior of male juvenile macaques. Journal of Comparative and Physiological Psychology, 1968, 65, 466-471.

KLING, A. Effects of amygdalectomy on social affective behavior in non-human primates. In B. Eleftheriou (Ed.), The neurobiology of the amygdala. New York: Plenum, 1972.

Kling, L., Lancaster, J., \& Benitone, J. Amygdalectomy in the free ranging vervet. Journal of Psychiatric Research, 1970, 7, 191-207.

Klinger, J., \& Gloor, P. The connections of the amygdala and of the anterior temporal cortex in the human brain. Journal of Comparative Neurology, 1960, 115, 333-369.

KoHLE R, C. Habituation after dorsal hippocampal lesions: A test dependent phenomenon. Behavioral Biology, 1976, 18, 89-110. (a)

KoHLER, C. Habituation of the orienting response after medial and lateral septal lesions in the albino rat. Behavioral Biology, 1976, 16, 63-72. (b)

KomisarUK, B. R. The role of rhythmical brain activity in sensorimotor integration. In J. M. Sprague \& A. N. Epstein (Eds.), Progress in psychobiology and physiological psychology (Vol. 7). New York: Academic Press, 1977.

Komisaruk, B. R., \& BEYER, C. Responses of diencephalic neurons to olfactory bulb stimulation, odor, and arousal. Brain Research, 1972, 36, 153-170.

Koranyi, L., Endroczi, E., Lissak, K., \& Szepes, E. The effect of ACTH on behavioral processes motivated by fear in mice. Physiology \& Behavior, 1967, 2, 439-445.

Kratz, K. E., \& Mitchell, J. C. Internal and external cue use following septal ablation in the rat. Physiological Psychology, $1977,5,177-180$.

LanCaster, J., \& Johnson, D. A. Effects of anterior, posterior, medial, lateral, and total septal lesions upon fixed ratio performance in the rat. Physiology \& Behavior, 1976, 17, 1-7.

LANDFIELD, P. W. Different effects of post-trial driving or blocking of the theta rhythm on avoidance learning in rats. Physiology \& Behavior, 1977, 18, 439-445.

LASH, L. Response discriminability and the hippocampus. Journal of Comparative and Physiological Psychology, 1964, 57, 251-256.

LEung, P. M. B., \& Rogers, Q. R. Effect of amygdaloid lesions on dietary intake of disproportionate amounts of amino acids. Physiology \& Behavior, 1973, 10, 221-226.

Levine, M. D., Gordon, T. P., Peterson, R. H., \& Rose, R. M. Urinary 17-OHCS response of high and low aggressive rhesus monkeys to shock avoidance. Physiology \& Behavior, 1970, 5, 919-924.

Livesey, P. J. Fractionation of hippocampal function in learning. 
In R. L. Isaacson \& K. H. Pribram (Eds.), The hippocampus (Vol. 2): Neurophysiology and behavior. New York: Plenum, 1975.

Lovely, R. H., Grossen, N. E., Moot, S. A., \& Peterson, I. J. Hippocampal lesions and inhibition of avoidance behavior. Journal of Comparative and Physiological Psychology, 1971, 77, 345-352.

Lubar, J. F., Brener, J. M., Deagle, J. H., Numan, R., \& Clemons, W. J. Effect of septal lesions on detection threshold and unconditioned response to shock. Physiology \& Behavior, $1970,5,459-464$.

Lyon, D. O., \& Millar, R. D. Conditional suppression on a FI schedule of reinforcement. Psychonomic Science, 1969, 17, 31-32.

Mandle R, G. Organization and memory. In K. W. Spence \& J. T. Spence (Eds.), The psychology of learning and motivation (Vol. 1). New York: Academic Press, 1967.

Margules, D. L., \& Olds, J. Identical feeding and rewarding systems in the lateral hypothalamus of rats. Science, 1962, 135, 374-375.

Mark, V. H., Ervin, F. R., \& Sweet, W. H. Deep temporal lobe stimulation. In B. Eleftheriou (Ed.), The neurobiology of the amygdala. New York: Plenum, 1972.

MarSden, H. M., \& Slotnick, B. M. Behavior following septal forebrain lesions in a social group of mice. American Zoologist, 1972, 12, 360.

Martini, L., Motta, M., \& Fraschini, F. The hypothalamus. New York: Academic Press, 1970.

McAlister, W., McAliste r, D. C., \& Douglas, W. K. The inverse relationship between shock intensity and shuttle box avoidance in rats. Journal of Comparative and Physiological Psychology, 1971, 74, 426-433.

MCCleary, R. A. Response functions of the limbic system. In E. Stellar \& J. Sprague (Eds.), Progress in physiological psychology (Vol. 1). New York: Academic Press, 1966.

McDonough, J. H., \& Manning, F. J. The effects of lesions in amygdala or dorsomedial frontal cortex on reinforcement omission and noncontingent reinforcement in rats. Physiological Psychology, 1979, 7, 167-172.

McEwen, B. S., \& Pfaff, D. W. Factors influencing sex hormone uptake by rat brain regions I. Effects of neonatal treatment, hypophysectomy, and competing steroid on estradiol uptake. Brain Research, 1970, 21, 1-16.

McGinnis, M., Nance, P. M., \& Gorski, R. A. Olfactory, septal, and amygdala lesions alone or in combination: Effects of lordosis behavior and emotionality. Physiology \& Behavior, $1978,20,435-440$.

McGowan, B. K., Hankins, W. G., \& Garcia, J. Limbic lesions and control of the internal and external environment. Behavioral Biology, 1972, 7, 841-852.

MEYER, V., \& KNOBIL, E. Growth hormone secretion in the unanesthetized rhesus monkey in response to noxious stimuli. Endocrinology, 1967, 80, 163-171.

Meudell, P., Butters, S., \& Montgomery, K. The role of rehearsal in the short term memory performance of patients with Korsakoff's and Huntington's diseases. Neuropsychologia, $1978,16,507-510$.

Micco, D. J., McEwen, B. S., \& Shein, W. Modulation of behavioral inhibition in appetitive extinction following manipulation of adrenal steroids in rats: Implications for involvement of the hippocampus. Journal of Comparative and Physiological Psychology, 1979, 93, 323-329.

Miller, J. W., \& Groves, P. M. Sensory evoked neuronal activity in the hippocampus before and after lesions of the medial septal nuclei. Physiology \& Behavior, 1977, 18, 141-146.

Milner, B., Corkin, S., \& Tauber, H. C. Further analysis of hippocampal amnesics syndrome: 14 year follow-up study of H. M. Neuropsychologia, 1968, 6, 215-234.

Mogenson, G. J., \& Phillips, A. G. Motivation: A psychological construct in search of a physiological substrate. In J. M.
Sprague \& A. N. Epstein (Eds.), Progress in psychobiology and physiological psychology (Vol. 6). New York: Academic Press, 1976.

Moore, J. W. Brain processes and conditioning. In A. Dickinson \& R. A. Boakes (Eds.), Mechanisms of learning and motivation: A memorial volume to Jerzy Konorski. Hillsdale, N.J: Erlbaum, 1979.

Morgan, M. J., \& Firsoff, G. I. A comparison between the reinforcing and discrimination functions of a stimulus. Learning and Motivation, 1970, 1, 248-260.

Morris, D. Manwatching. New York: Harry Abrams, 1977.

Munoz, C., \& Grossman, S. P. Behavioral consequences of selective destruction of neuron perikarya in septal area of rats. Physiology \& Behavior, 1980, 24, 779-788.

Murphy, J. T., Dreifuss, J. J., \& Gloor, P. Responses of hypothalamic neurons to repetitive amygdaloid stimulation. Brain Research, 1968, 8, 153-167.

NADEL, L. Dorsal and ventral hippocampal lesions and behavior. Physiology \& Behavior, 1968, 3, 891-900.

NAdEL, L., \& O'KeEFE, J. The hippocampus in pieces and patches: An essay on modes of explanation in physiological psychology. In R. Bellairs \& E. G. Gray (Eds.), Essays on the nervous system: A festschrift for Professor J. Z. Young. Oxford: Clarendon Press, 1974.

NARABAyAshi, H. Stereotaxic amygdalotomy. In B. Eleftheriou (Ed.), The neurobiology of the amygdala. New York: Plenum, 1972.

Nonneman, A. J., \& KolB, B. E. Lesions of hippocampus or prefrontal cortex alter species-typical behavior in the cat. $B e$ havioral Biology, 1974, 12, 41-54.

Norton, P. R. E. Differences in the electrophysiological correlates upon receipt of a food reward and nonreward in the rat. Brain Research, 1970, 24, 134-138.

Numan, R. Cortical-limbic mechanisms and response control: A theoretical review. Physiological Psychology, 1978, 6, 445-470.

O'KeEFe, J., \& BoumA, H. Complex sensory properties of certain amygdala units in the freely moving cat. Experimental Neurology, 1969, 23, 384-398.

O'Keefe, J., \& Dostrovsky, J. The hippocampus as a spatial map: Preliminary evidence from unit activity in the freely moving rat. Brain Research, 1971, 34, 171-175.

O'KeEFE, J., \& NADEL, L. The hippocampus as a cognitive map. Oxford: Oxford University Press, 1978.

OLDS, J. A preliminary mapping of electrical reinforcing effects in the rat brain. Journal of Comparative and Physiological Psychology, 1956, 49, 281-285.

Oscar-Berman, M. O. Hypothesis testing and focusing behavior during concept formation by amnesic Korsakoff patients. Neuropsychologia, 1973, 11, 191-198.

Owens, G., \& Williams, M. Factors affecting the sense of familiarity with cue elicited responses in amnesic patients. Neuropsychologia, 1980, 18, 85-87.

Pagano, R. R., \& Goult, F. P. Amygdala activity: A central measure of arousal. Electroencephalography and Clinical Neurophysiology, 1964, 17, 255-260.

Papez, J. W. A proposed mechanism of emotion. AMA Archives of Neurology and Psychiatry, 1937, 38, 725-743.

Parmeggiani, P. L., \& Rapisardi, C. Hippocampal output and sensory mechanisms. Brain Research, 1969, 14, 387-400.

Pasley, J. N., Powell, E. W., Cernosek, R. M., \& Cernosek, S. F. Effects of amygdaloid lesions on reproductive function of grouped caged mice. Neuroendocrinology, 1978, 25, 77-83.

Pavlov, I. P. Lectures on conditioned reflexes (Vol. 2): Conditioned reflexes and psychiatry (W. H. Gantt, trans.). New York: International, 1941.

Penfield, W., \& Perot, P. The brain's record of auditory and visual experience-A final summary and discussion. Brain, 1963, 86, 595-696.

Peterson, G. B., Ackil, J., Frommer, G. P., \& Hearst, E. 
Conditioned approach and contact behavior toward signals for food or brain stimulation reinforcement. Science, 1972, 177, 1009.

Pfaff, D., Lewis, C., Diakow, C., \& Keiner, M. Neurophysiological analysis of mating behavior responses as hormone sensitive reflexes. In E. Stellar \& J. M. Sprague (Eds.), Progress in physiological psychology (Vol. 5). New York: Academic Press, 1973.

Plunkett, R. P., \& Foulds, B. D. The effect of cue distinctiveness on successive discrimination performance in hippocampally lesioned rats. Physiological Psychology, 1979, 7, 49-52.

Poplawsky, A., \& Hoffman, S. L. Effects of lateral, medial, or complete septal lesions on response suppression. Physiology \& Behavior, 1979, 22, 679-682.

RaIsman, G. The connections of the septum. Brain, 1966, 317-348.

RANCK, J. B. Studies on single neurons in the dorsal hippocampal formation and septum in unrestrained rats. Part I: Behavioral correlates and firing repertoires. Experimental Neurology, 1973, 41, 461-531.

RANCK, J. B. Behavioral correlates and firing repertoires of neurons in the dorsal hippocampal formation and septum of unrestrained rats. In R. L. Isaacson \& K. H. Pribram (Eds.), The hippocampus (Vol. 2): Neurophysiology and behavior. New York: Plenum, 1975.

REDGATE, E. S. ACTH release evoked by electrical stimulation of brain stem and limbic system sites in the cat: The absence of ACTH release upon infundibular area stimulation. Endocrinology, 1970, 86, 806-823.

Rescorla, R. A. Pavlovian conditioning and its proper control procedures. Psychological Review, 1967, 74, 71-80.

RESCORLA, R. A. Informational variables in Pavlovian conditioning. In G. H. Bower (Ed.), The psychology of learning and motivation (Vol. 6). New York: Academic Press, 1972.

RESCORLA, R. A. Second order conditioning: Implications for theories of learning. In F. J. McGuigan \& D. B. Lumsden (Eds.), Contemporary approaches to conditioning and learning. Washington, D.C: Winston, 1973.

Rescorla, R. A., \& Wagner, A. R. A theory of Pavlovian conditioning: Variations in the effectiveness of reinforcement and non-reinforcement. In A. Black \& W. F. Prokasy (Eds.), Classical conditioning II: Current theory and research. New York: Appleton, 1972.

Rizley, R. C., \& Rescorla, R. A. Associations in second order conditioning and sensory preconditioning. Journal of Comparative and Physiological Psychology, 1972, 81, 1-11.

Robinson, T. E., \& VANDERwolf, C. H. Electrical stimulation of the brain stem in freely moving rats II. Effects on hippocampal and neocortical electrical activity and relations to behavior. Experimental Neurology, 1978, 61, 485-515.

Rolls, E. T. Activation of amygdaloid neurones in reward, eating, or drinking elicited by electrical stimulation of the brain. Brain Research, 1972, 45, 365-381.

Rolls, E. T., Burton, M. J., \& Mora, F. Hypothalamic neuronal responses associated with the sight of food. Brain Research, 1976, 111, 53-66.

Rolls, E. T., \& Rolls, B. J. Altered food preference after lesions of the basolateral region of the amygdala in the rat. Journal of Comparative and Physiological Psychology, 1973, 83, 248-259.

Rubin, R. T., Mandell, A. J., \& Crandall, P. H. Corticosteroid responses to limbic stimulation in man: Localization of stimulus sites. Science, 1966, 153, 767-768.

Salafia, W. R., Romanov, A. G., Tynan, T., \& Host, K. Disruption of rabbit (Oryctolagus cuniculus) nictitating membrane conditioning by posttrial electrical stimulation of the hippocampus. Physiology \& Behavior, 1977, 18, 207-212.

Saltzman, I. J. Maze learning in the absence of primary reinforcement: A study of secondary reinforcement. Journal of Comparative and Physiological Psychology, 1949, 42, 161-172.
Sanghera, M. K., Rolls, E. T., \& Roper-Hall, A. Visual responses of neurons in the dorsolateral amygdala of the alert monkey. Experimental Neurology, 1979, 63, 610-626.

Schmaltz, L. W., \& Theios, J. Acquisition and extinction of a classically conditioned response in hippocampectomized rabbits (Oryctolagus cuniculus). Journal of Comparative and Physiological Psychology, 1972, 79, 328-333.

Schreine R, L., \& KLing, A. Behavioral changes following rhinencephalic injury in cats. Journal of Neurophysiology, 1953, 16, 643-659.

Schulman, A. Word length and rarity in recognition memory. Psychonomic Science, 1967, 9, 211-212.

Schwartzbaum, J. S. Some effects of amygdaloid hyperphagia. American Journal of Psychology, 1961, 74, 252-259.

Schwartzbaum, J. S., \& Donovick, P. J. Discrimination reversal and spatial alternation associated with septal and caudate disfunction in rats. Journal of Comparative and Physiological Psychology, 1968, 65, 83-92.

SchwartzBaUm, J. S., \& GAY, M. Interaction of septum and amygdala. Journal of Comparative and Physiological Psychology, 1966, 71, 59-68.

Schwartzbaum, J. S., \& Spieth, T. M. Analysis of the response inhibition concept of septal function in passive avoidance behavior. Psychonomic Science, 1964, 1, 145-146.

Scoville, W. B., Dunsmore, R. H., Liberson, W. T., Henry, C. E., \& PEPE, A. Observations on medial temporal lobotomy uncotomy in the treatment of psychotic states. Proceedings of the Association on Research in Nervous and Mental Disease, $1953,31,347$.

Segal, M. A potent inhibitory monosynaptic hypothalamohippocampal connection. Brain Research, 1979, 162, 137-141.

SEmBA, K., \& IwAHORAs, E. Effects of medial septal lesions on the hippocampal electrical activity and orienting response to auditory stimulation in drinking rats. Brain Research, 1974, 66, 309-320.

Semba, K., \& Komisaruk, B. R. Phase of the theta wave in relation to different limb movements in awake rats. Electroencephalography and Clinical Neurophysiology, 1978, 44, 61-71.

ShetTLEworTh, S. J. Reinforcement and the organization of behavior in hamsters: Hunger, environment and food reinforcement. Journal of Experimental Psychology: Animal Behavior Processes, 1975, 1, 56-88.

Shipley, J. E., \& Kolb, B. Neural correlates of species typical behavior in the Syrian golden hamster. Journal of Comparative and Physiological Psychology, 1977, 91, 1056-1073.

Sinnamon, H. M., Freniere, S., \& Kootz, J. Rat hippocampus and memory for places of changing significance. Journal of Comparative and Physiological Psychology, 1978, 92, 142-155.

Slotnick, B. M. Fear behavior and passive avoidance deficits in mice with amygdala lesions. Physiology \& Behavior, 1973, 11, 717-720.

Smith, G. P. Adrenal hormones and emotional behavior. In E. Stellar \& J. M. Sprague (Eds.), Progress in physiological psychology. New York: Academic Press, 1973.

Smotherman, W. P., Hennesy, J. W., \& Levine, S. Plasma corticosterone levels during recovery from $\mathrm{LiCl}$ produced taste aversion. Behavioral Biology, 1976, 16, 401-412.

Sodetz, F. J. Septal ablation and free operant avoidance behavior in the rat. Physiology \& Behavior, 1970, 5, 773-778.

Sokolov, E. N. The modeling properties of the nervous system. In M. Cole \& I. Maltzman (Eds.), A handbook of contemporary Soviet psychology. New York: Basic Books, 1969.

Solomon, P. R. Role of the hippocampus in blocking and conditioning inhibition of the rabbit's nictitating membrane response. Journal of Comparative and Physiological Psychology, 1977, 91, 405-417.

Solomon, P. R., \& Moore, J. Latent inhibition and stimulus generalization of the classical conditioning nictitating membrane response in rabbits (Oryctolagus cuniculus) following dorsal 
hippocampal ablation. Journal of Comparative and Physiological Psychology, 1975, 89, 1192-1203.

Spevack, A. A., Campbell, C. T., \& Drake, L. Effect of amygdalectomy on habituation and CER in rats. Physiology \& Behavior, 1975, 15, 199-207.

Spevack, A. A., \& Pribram, K. H. Decisional analysis of the effects of limbic lesions on learning in monkeys. Journal of Comparative and Physiological Psychology, 1973, 82, 211-226.

Squire, L. R., \& Slater, P. C. Anterograde and retrograde memory impairment in chronic amnesia. Neuropsychologia, 1978, 16, 313-322.

Stevens, J. R., Mark, V. H., Erwin, F., Pacheco, P., \& Suematsu, K. Deep temporal stimulation in man. Archives of Neurology, 1969, 21, 157-169.

STUMPF, L. Drug action on the electrical activity of the hippocampus. International Review of Neurobiology, 1965, 8, 77-138.

STUMPF, W. E., \& SAR, M. Estradiol concentrating neurons in the amygdala. Proceedings of the Society for Experimental Biology and Medicine, 1971, 136, 102-106.

Suess, W. M., \& Berlyne, D. E. Exploratory behavior as a function of hippocampal damage, stimulus complexity, and stimulus novelty in the hooded rat. Behavioral Biology, 1978, 23, 487-499.

Swanson, L. W., \& Cowan, W. M. An autoradiographic study of the organization of the efferent connections of the hippocampal formation in the rat. Journal of Comparative Neurology, 1977, 19, 1153-1158.

Swanson, L. W., \& Cowan, W. M. The connections of the septal region in the rat. Journal of Comparative Neurology, 1979, 186, 621-656.

Talland, G. A. Deranged memory. New York: Academic Press, 1965.

TARR, R. S. Role of the amygdala in the intraspecies aggressive behavior of the Iguanid lizard Sceloparus occidentalis. Physiology \& Behavior, 1977, 19, 1153-1158.

Terasawa, E., \& Timiras, P. S. Electrical activity during the estrous cycle of the rat: Cyclic changes in limbic structures. Endocrinology, 1968, 83, 207-216.

Terrace, H. S. Escape from S-. Learning and Motivation, 1971, 2, 148-163.

ThомAs, J. B. Stimulus perseveration and choice behavior in rats with septal lesions. Journal of Comparative and Physiological Psychology, 1972, 80, 97-105.

Thompson, C. I., Bergland, R. M., \& Towfight, J. T. Social and nonsocial behaviors of adult rhesus monkeys after amygdalectomy in infancy and adulthood. Journal of Comparative and Physiological Psychology, 1977, 91, 533-548.

Thompson, R. F. Foundations of physiological psychology. New York: Harper \& Row, 1967.

Tulving, E. Ecphoric processes in recall and recognition. In J. Brown (Ed.), Recall and recognition. New York: Wiley, 1976.

Uhlir, I., Seggie, J., \& Brown, G. M. The effect of septal lesions on the threshold of adrenal stress response. Neuroendocrinology, 1974, 14, 351-355.

UNDE RWOOD, B. J. Attributes of memory. Psychological Review, 1969, 76, 559-573.

Ursin, H., \& Divac, I. Emotional behavior in feral cats with ablations of prefrontal cortex and subsequent lesions in amygdala. Journal of Comparative and Physiological Psychology, 1975, 88, 36-39.

UrSIN, H., \& KAADA, B. R. Subcortical structures mediating the attention response induced by amygdala stimulation. Experimental Neurology, 1960, 2, 109-122.

URSIN, H., WEBSTER, K., \& URSin, R. Habituation to electrical stimulation of the brain in unanesthetized cats. Electroencephalography and Clinical Neurophysiology, 1967, 23, 41-49.

Usher, D. R., Lieblich, I., \& Siegel, R. A. Pituitary-adrenal function after large and small lesions in the lateral septal area in food deprived rats. Neuroendocrinology, 1974, 16, 156-164.

VAlenste in, E. Brain control. New York: Wiley, 1973.
VANDERWOLF, C. H. Limbic-diencephalic mechanisms of voluntary movement. Psychological Review, 1971, 78, 83-113.

Vande rwolf, C. H., Kramis, R., Gillespie, L. A., \& Bland, B. H. Hippocampal slow activity and neocortical low voltage fast activity: Relations to behavior. In R. L. Isaacson \& K. H. Pribram (Eds.), The hippocampus (Vol. 2): Neurophysiology and behavior. New York: Plenum, 1975.

VANDERWOLF, C. H., \& VANDERWART, M. L. Relations of heart rate to motor activity and arousal in the rat. Canadian Journal of Psychology, 1970, 24, 434-441.

VAN HARTESveld, $C$. The hippocampus and regulation of the hypothalamic-hypophyseal-adrenal cortical axis. In R. L. Isaacson \& K. H. Pribram (Eds.), The hippocampus (Vol. 1): Structure and development. New York: Plenum, 1975.

Vinogradova, $\mathbf{O}$. S. The hippocampus and the orienting reflex. In E. N. Sokolov \& O. S. Vinogradova (Eds.), Neuronal mechanisms of the orienting reflex. Hillsdale, N.J: Erlbaum, 1975.

Vom SaAl, F. S., Hamilton, L. W., \& Gandelman, R. J. Faster acquisition of an olfactory discrimination following septal lesions in male albino rats. Physiology \& Behavior, 1975, 14, 697-703.

WALKE R, D. W., \& MEANS, L. W. Single alternation performance in rats with hippocampal lesions: Disruption by an irrelevant task interposed during the intertrial interval. Behavioral Biology, 1973, 9, 93-104.

Warrington, E. K., \& Weiskrantz, L. A study of learning and retention in amnesic patients. Neuropsychologia, 1968, 6, 283-291.

Warrington, E. K., \& Weiskrantz, L. Further analysis of the prior learning effect in amnesia patients. Neuropsychologia, 1978, 16, 169-177.

Weiskrantz, L., \& Warrington, E. K. Verbal learning and retention in amnesic patients using partial information. Psychonomic Science, 1970, 20, 210-211.

Weiskrantz, L., \& Warrington, E. K. The problem of the amnesic syndrome in man and animals. In R. L. Isaacson \& K. H. Pribram (Eds.), The hippocampus (Vol. 2): Neurophysiology and behavior. New York: Plenum, 1975.

Werka, T., Skar, J., \& Ursin, H. Exploration and avoidance in rats with lesions in amygdala and piriform cortex. Journal of Comparative and Physiological Psychology, 1978, 92, 672-681.

Wetzel, W., OtT, T., \& Matthies, H. Hippocampal rhythmic slow wave activity (theta) and behavior elicited by medial septal stimulation in rats. Behavioral Biology, 1977, 19, 534-542. (a)

Wetzel, W., OtT, T., \& Matrhies, H. Post-training hippocampal rhythmic slow activity (theta) elicited by septal stimulation improves memory consolidation in rats. Behavioral Biology, $1977,21,32-40$. (b)

Whishaw, I. W., \& VANDE RWOLF, C. H. Hippocampal correlates of movement. Proceedings of the Canadian Federation of Biological Societies, 1970, 13, 48.

White, N. Perseveration by rats with amygdaloid lesions. Journal of Comparative and Physiological Psychology, 1971, 77, 450-456.

White, N. M., \& Fisher, A. E. Relationship between amygdala and hypothalamus in the control of eating behavior. Physiology \& Behavior, 1969, 4, 199-205.

Wickelgren, W. O., \& IsAacson, R. L. Effect of the introduction of an irrelevant stimulus on runway performance of the hippocampectomized rat. Nature, 1963, 200, 48-50.

WiCkens, D. C. Encoding categories of words: An empirical approach to meaning. Psychological Review, 1970, 77, 1-15.

Williams, D. R. Classical conditioning and incentive motivation. In W. F. Prokasy (Ed.), Classical conditioning: $A$ symposium. New York: Appleton, 1965.

Wilson, M., \& Critchlow, V. Effect of fornix transection and hippocampectomy on rhythmic pituitary-adrenal function in the rat. Neuroendocrinology, 1973, 13, 29-40.

Winocur, G. The effects of interference on discrimination learning and recall by rats with hippocampal lesions. Physiology \& Behavior, 1979, 22, 339-345. 
Winocur, G., \& Bindra, D. Effects of additional cues on passive avoidance learning and extinction in rats with hippocampal lesions. Physiology \& Behavior, 1976, 17, 915-920.

Winocur, G., \& BlAck, A. H. Cue induced recall of a passive avoidance response by rats with hippocampal lesions. Physiology \& Behavior, 1978, 21, 39-44.

Winocur, G., \& Breckinridge, C. B. Cue dependent behavior of hippocampally lesioned rats in a complex maze. Journal of Comparative and Physiological Psychology, 1973, 82, 512-522.

Winocur, G., \& Kinsbourne, M. Contextual cueing as an aid to Korsakoff amnesics. Neuropsychologia, 1978, 16, 671-682.

Winson, J. Interspecies differences in the occurrence of theta. Behavioral Biology, 1972, 7, 479-487.

Wishart, T., \& Mogenson, G. Effects of lesions of the hippo- campus and septum before and after passive avoidance training. Physiology \& Behavior, 1970, 5, 31-34.

ZoLovick, A. J. Effects of lesions and electrical stimulation of the amygdala on hypothalamic-hypophyseal regulation. In B. Eleftheriou (Ed.), The neurobiology of the amygdala. New York: Plenum, 1972.

Zuromski, E. S., Donovick, P. J., \& Burright, R. G. Barpressing for illumination change in albino rats with septal lesions. Journal of Comparative and Physiological Psychology, 1972, 78, 83-90.

(Received for publication August 28, 1979; revision accepted October 7,1980 .) 